\title{
Inhibition of hyaluronan synthesis restores immune tolerance during autoimmune insulitis
}

\author{
Nadine Nagy, ${ }^{1}$ Gernot Kaber, ${ }^{1}$ Pamela Y. Johnson, ${ }^{2}$ John A. Gebe, ${ }^{2}$ Anton Preisinger, ${ }^{2}$ Ben A. Falk, ${ }^{2}$ Vivekananda G. Sunkari, ${ }^{1}$ \\ Michel D. Gooden, ${ }^{2}$ Robert B. Vernon, ${ }^{2}$ Marika Bogdani, ${ }^{2}$ Hedwich F. Kuipers, ${ }^{1}$ Anthony J. Day, ${ }^{3}$ Daniel J. Campbell, ${ }^{4}$ \\ Thomas N. Wight, ${ }^{2}$ and Paul L. Bollyky' \\ 'Division of Infectious Diseases and Geographic Medicine, Department of Medicine, Stanford University School of Medicine, Stanford, California, USA. ${ }^{2}$ Matrix Biology Program, Benaroya Research Institute, \\ Seattle, Washington, USA. 'Wellcome Trust Centre for Cell-Matrix Research, Faculty of Life Sciences, University of Manchester, Manchester, United Kingdom. ${ }^{4}$ Immunology Program, \\ Benaroya Research Institute, Seattle, Washington, USA.
}

\begin{abstract}
We recently reported that abundant deposits of the extracellular matrix polysaccharide hyaluronan (HA) are characteristic of autoimmune insulitis in patients with type 1 diabetes (T1D), but the relevance of these deposits to disease was unclear. Here, we have demonstrated that HA is critical for the pathogenesis of autoimmune diabetes. Using the D011.10xRIPmOVA mouse model of T1D, we determined that HA deposits are temporally and anatomically associated with the development of insulitis. Moreover, treatment with an inhibitor of HA synthesis, 4-methylumbelliferone (4-MU), halted progression to diabetes even after the onset of insulitis. Similar effects were seen in the NOD mouse model, and in these mice, 1 week of treatment was sufficient to prevent subsequent diabetes. 4-MU reduced HA accumulation, constrained effector T cells to nondestructive insulitis, and increased numbers of intraislet FOXP3 ${ }^{+}$Tregs. Consistent with the observed effects of 4-MU treatment, Treg differentiation was inhibited by HA and anti-CD44 antibodies and rescued by 4-MU in an ERK1/2-dependent manner. These data may explain how peripheral immune tolerance is impaired in tissues under autoimmune attack, including islets in T1D. We propose that 4-MU, already an approved drug used to treat biliary spasm, could be repurposed to prevent, and possibly treat, T1D in at-risk individuals.
\end{abstract}

\section{Introduction}

Autoimmune type 1 diabetes (T1D) is characterized by progressive, immune cell-mediated destruction of pancreatic $\beta$ cells and the failure of regulatory mechanisms that normally prevent destructive insulitis, including $\mathrm{FOXP}^{+}$Tregs $(1,2)$. The local tissue environment is thought to contribute to immune regulation and the development of T1D (3-5), but the relevant mechanisms are unclear.

Recently, we reported (6) that autoimmune insulitis in T1D was associated with islet-specific deposition of hyaluronan (HA), an extracellular matrix (ECM) polysaccharide thought to contribute to chronic inflammation in a variety of settings (7-9). Using human T1D tissue samples from cadaveric organ donors obtained through the Juvenile Diabetes Research Foundation (JDRF) Network for Pancreatic Organ Donors with Diabetes (nPOD) program, we discovered that HA deposits were present in islets from donors with recent-onset T1D but not in those with longstanding T1D or type 2 diabetes or nondiabetic controls.

These T1D-associated HA deposits were also linked with local alterations in molecules that bind to HA, including TNFstimulated gene-6 (TSG6), and inter- $\alpha$-inhibitor ( $\alpha \mathrm{I}$ ). There is increasing evidence that HA/I $\alpha$ / TSG6 complexes have powerful tissue-protecting effects and that the precise organization of the HA matrix in vivo dictates its functional effect (10-12). Together, these data implicated HA and the islet ECM in the onset of T1D.

Conflict of interest: The authors have declared that no conflict of interest exists. Submitted: September 30, 2014; Accepted: August 6, 2015.

Reference information: J Clin Invest. 2015;125(10):3928-3940. doi:10.1172/JCI79271.
However, it was unclear from these previous studies whether HA deposition preceded or merely followed autoimmune insulitis or whether HA contributed to diabetes pathogenesis.

To address these questions, we turned to a highly predictable and synchronous model of T1D, the DO11.10xRIPmOVA (DORmO) mouse model. These mice are the offspring of DO11.10 and RIPmOVA transgenic mice. They carry a $\mathrm{T}$ cell receptor transgene specific for OVA (emulating autoreactive $\mathrm{CD} 4^{+} \mathrm{T}$ cells), while simultaneously expressing OVA in conjunction with the insulin gene promoter on pancreatic $\beta$ cells (emulating the autoantigen). DORmO mice spontaneously develop autoimmune insulitis starting at 4 weeks of age, with nearly $100 \%$ becoming diabetic by 20 weeks of age (13).

To define the contributions of HA to insulitis, we treated these animals with 4-methylumbelliferone (4-MU), a pharmacologic inhibitor of HA synthesis (14). Treating DORmO mice with 4-MU provided us with a synchronous model of T1D in which disease progression could be manipulated and monitored. 4-MU treatment was also assessed in NOD mice. Along with providing us with another mouse model of T1D, autoimmune insulitis in these animals is thought to share similarities with that seen in human T1D (15).

Using these models, we tested the hypotheses that HA is fundamentally required for progression of autoimmune insulitis and that pharmacologic inhibition of HA synthesis may prevent progression of autoimmune diabetes.

\section{Results}

DORmO mice develop progressive, HA-associated insulitis. DORmO mice developed autoimmune insulitis at approximately 4 weeks 

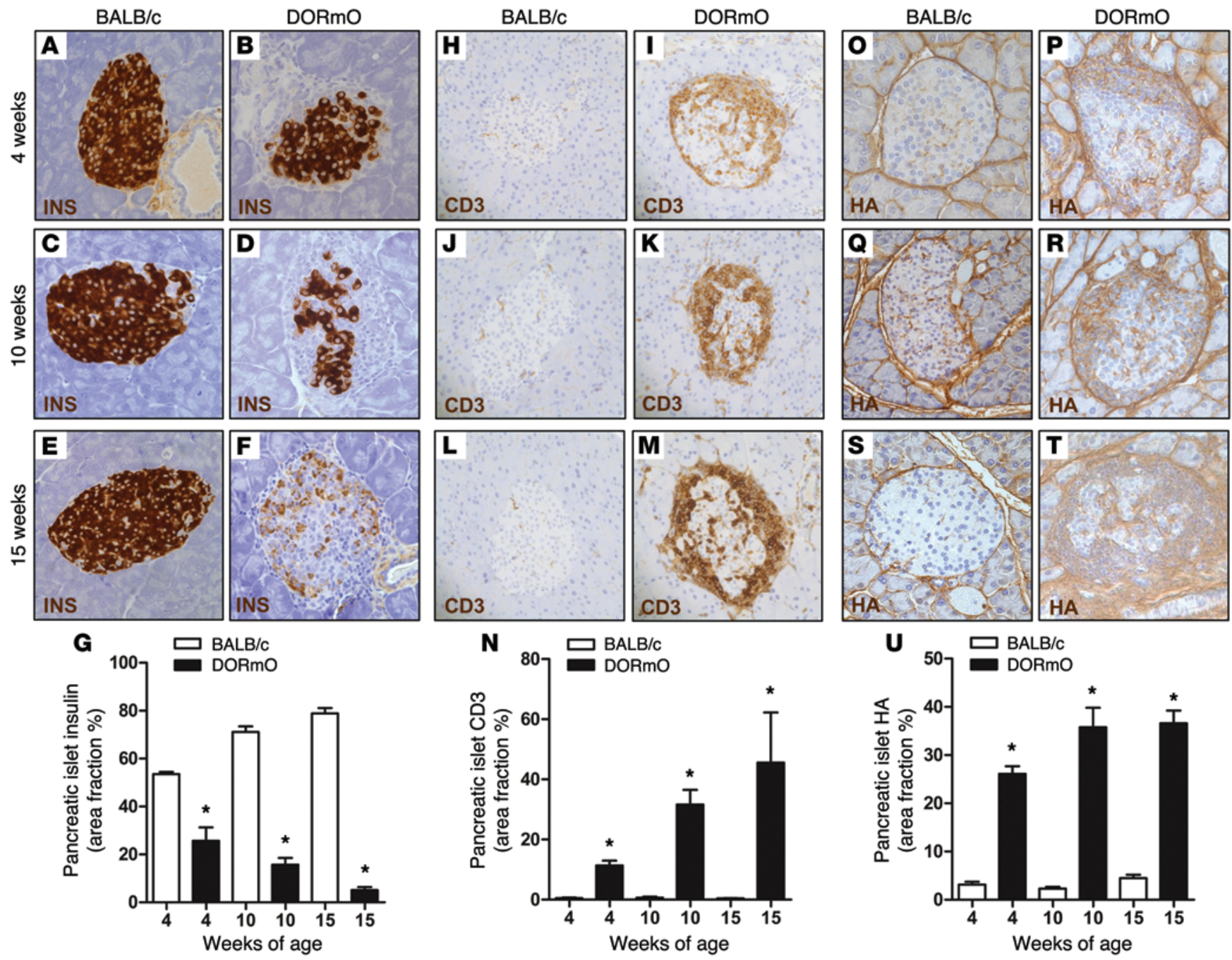

Figure 1. Islet HA accumulates in tandem with progressive autoimmune insulitis in DORmO mice. Representative histologic staining of pancreatic tissue from BALB/c (control) and DORmO mice and average islet area positive over time for (A-G) insulin (INS), (H-N) CD3, and (O-U) HA. For G, N, and U, at least 25 islets were visualized per mouse, and staining and data are from $n=6-8$ mice per condition. Original magnification, $\times 40$. Data represent mean \pm SEM; ${ }^{*} P<0.05$ vs. control for each time point by unpaired $t$ test.

of age, with nearly all mice becoming diabetic (blood glucose $>250 \mathrm{mg} / \mathrm{dl}$ ) by 20 weeks of age (Supplemental Figure 1A; supplemental material available online with this article; doi:10.1172/ JCI79271DS1). This pattern was observed irrespective of gender (Supplemental Figure 1B) or weight (Supplemental Figure 1C). The production of insulin by the islets progressively decreased over time (Figure 1, A-G, and Supplemental Figure 1D), while lymphocytic $\left(\mathrm{CD}^{+}\right)$infiltrates increased (Figure $1, \mathrm{H}-\mathrm{N}$ ).

Alongside these changes, the average islet area that stained positive for $\mathrm{HA}$ increased markedly during the progression to diabetes in DORmO mice (Figure 1, O-U). HA peaked at approximately 12 weeks of age (Figure 2A), around the time that these animals typically first become hyperglycemic (Supplemental Figure 1A). Our biochemical analyses indicated that at 15 weeks pancreatic HA content was nearly double that seen in control (BALB/c) mice (Figure 2B).

To discern whether the increase in islet HA was associated with increased synthesis or reduced catabolism of $\mathrm{HA}$, we evaluated the expression of HA synthase or degradative (hyaluronidase) enzymes. Analyses of islet mRNA from 8-week-old mice showed that HA synthase 3 (Has3) was upregulated, while hyaluronidase 1 (Hyal1) was downregulated. However, hyaluronidase 2 (Hyal2) expression was increased, while that of Rhamm and layilin, two HA receptors that contribute to HA clearance, was increased (Supplemental Figure 2, A-G). This complexity may reflect the multiple cell types present within inflamed islets, with potentially disparate patterns of HA synthesis and catabolism.

We asked whether HA was systemically increased in DORmO mice. Levels of circulating HA were unchanged (Figure 2C), and we did not see heightened HA deposition in the heart, lung, or liver (data not shown).

We also considered whether islet HA deposition was driven by hyperglycemia. Arguing against this, islet HA was increased at 4 weeks (Figure 2A), well before the onset of hyperglycemia (Supplemental Figure 1A). In hyperglycemic mice in which the etiology of diabetes was not autoimmune, namely mice treated with the $\beta$ cell toxin streptozotocin (STZ) (Figure 2D), and $d b / d b$ mice (Figure 2E), less intraislet HA was seen, and this was not associ- 

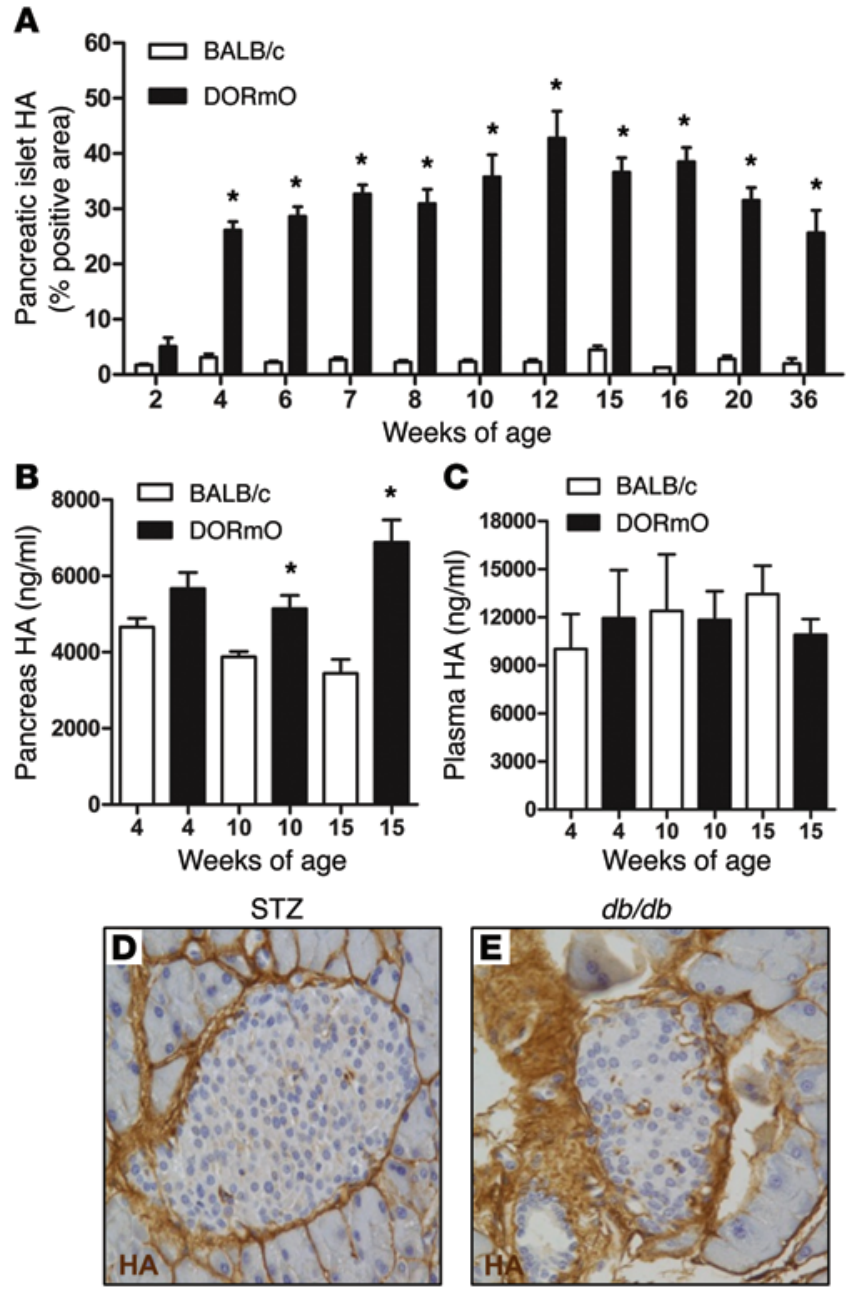

ated with insulitis (16). Consistent with this, we only observed substantial intraislet HA deposits in cadaveric islets from subjects with recent-onset T1D (6).

We next examined the relationship between HA and infiltrating lymphocytes during insulitis. In DORmO mice, we observed that HA was abundant in islets under autoimmune attack but was largely absent in neighboring islets without insulitis (Figure 3A). The same pattern was seen in islets in cadaveric human tissues (Figure 3B). In $\mathrm{BALB} / \mathrm{c}$ control mice without insulitis, HA was concentrated around vascular tissues and in the interstitial spaces (Figure 3, C and E). In contrast, HA in DORmO mice was most abundant around lymphocytic infiltrates (Figure 3, D and F). This distribution again mirrored patterns of HA deposition in human cadaveric pancreatic tissues from subjects with recent-onset T1D (Figure 3, G and H).

Together with our recently published work on human T1D (6), these data indicate that HA was temporally and anatomically associated with infiltrating lymphocytes in autoimmune diabetes.

It is notable that we observed some differences in the distribution of $\mathrm{HA}$ between mice and humans. In mice, a thin sheath of HA surrounded islets (Figure 3, C and E, and ref. 17), whereas this was less pronounced in humans (Figure 3, G and H). Furthermore, the progressive accumulation of HA during insulitis in DORmO mice was centripetal, spreading from the periphery of islets inward, while HA was more patchy in human T1D (Figure 3, G and H).
Figure 2. Islet HA deposition is temporally associated with insulitis and not hyperglycemia. (A) Percentage of islet area positive for HA staining of DORmO and BALB/C (control) mice over time $(n=6-15)$. (B) Pancreas and (C) plasma HA content in BALB/C and DORmO mice over time $(n=6)$. (D and E) Representative HA staining of pancreatic islet tissue from (D) a BALB/c mouse 1 week after STZ treatment and (E) a 12-week-old diabetic $d b / d b$ mouse. Original magnification, $\times 40$. Data represent mean $\pm S E M$; ${ }^{*} P<0.05$ vs. control for each time point by unpaired $t$ test.

These patterns mirror the known distribution and progression of insulitis in these two species (18).

Hyaladherins are altered during T1D progression. Along with changes in HA, we observed progressive alterations in both the amount and the distribution of hyaladherins in DORmO insulitis. Both TSG6 (Supplemental Figure 3, A-F, and S) and IaI (Supplemental Figure 3, G-L, and U) decreased in the DORmO pancreatic islets during disease progression. Tsg6 mRNA, however, was increased (Supplemental Figure 3T), while I $\alpha$ I-encoding mRNA expression decreased (Supplemental Figure 3V). Staining for versican was largely unchanged (Supplemental Figure 3, M-R, and W), but mRNA expression increased (Supplemental Figure 3X). These data indicate that insulitis was associated with extensive changes in the islet ECM.

4-MU treatment prevents progression to diabetes. While our data suggested that HA deposits are temporally and anatomically associated with insulitis, it was unclear whether HA contributed to disease pathogenesis. We therefore administered 4-MU to DORmO mice to test whether inhibition of HA synthesis could prevent autoimmune diabetes.

Adding 4-MU to chow significantly reduced HA content in DORmO islets (Figure 4, A-E). HA content was likewise reduced in isolated islets that were cultured overnight in 4-MU (Figure 4F). These data are consistent with the established role of 4-MU as an inhibitor of HA synthesis in other tissues $(19,20)$.

Together with this effect on HA, 4-MU treatment starting at 8 weeks of age prevented progression to hyperglycemia in DORmO mice (Figure $4 G$ ). Indeed, DORmO mice were normoglycemic during 4-MU treatment for up to a year, indicating that 4-MUmediated prevention of diabetes was sustainable and efficacious in this model over long periods of time.

Further, treatment of NOD mice with 4-MU for 1 week prevented the subsequent progression to hyperglycemia in these animals (Figure $4 \mathrm{H}$ ). Of note, insulitis is typically already well established in this model by the age at which mice were treated with 4-MU (5 weeks of age) (Supplemental Figure 4 and ref. 21). Moreover, HA deposition is also a feature of insulitis in NOD mice as well (16). These data indicate that 4-MU can prevent diabetes in multiple mouse models of T1D.

To evaluate whether 4-MU eliminated autoreactive T cells, we took DORmO mice made normoglycemic by 4-MU off of this drug. These mice rapidly became hyperglycemic (Figure 5A), suggesting that 4-MU suspends autoimmune destruction without eliminating the potential for autoimmunity.

To test whether 4-MU promoted regeneration of $\beta$ cells, we initiated 4-MU treatment at 12 weeks of age, by which time DORmO mice are typically borderline hyperglycemic and have substantially diminished $\beta$ cell mass. 4-MU treatment did not prevent the onset of diabetes in these animals (Figure $5 \mathrm{~B}$ ) or improve glycemic control, as 

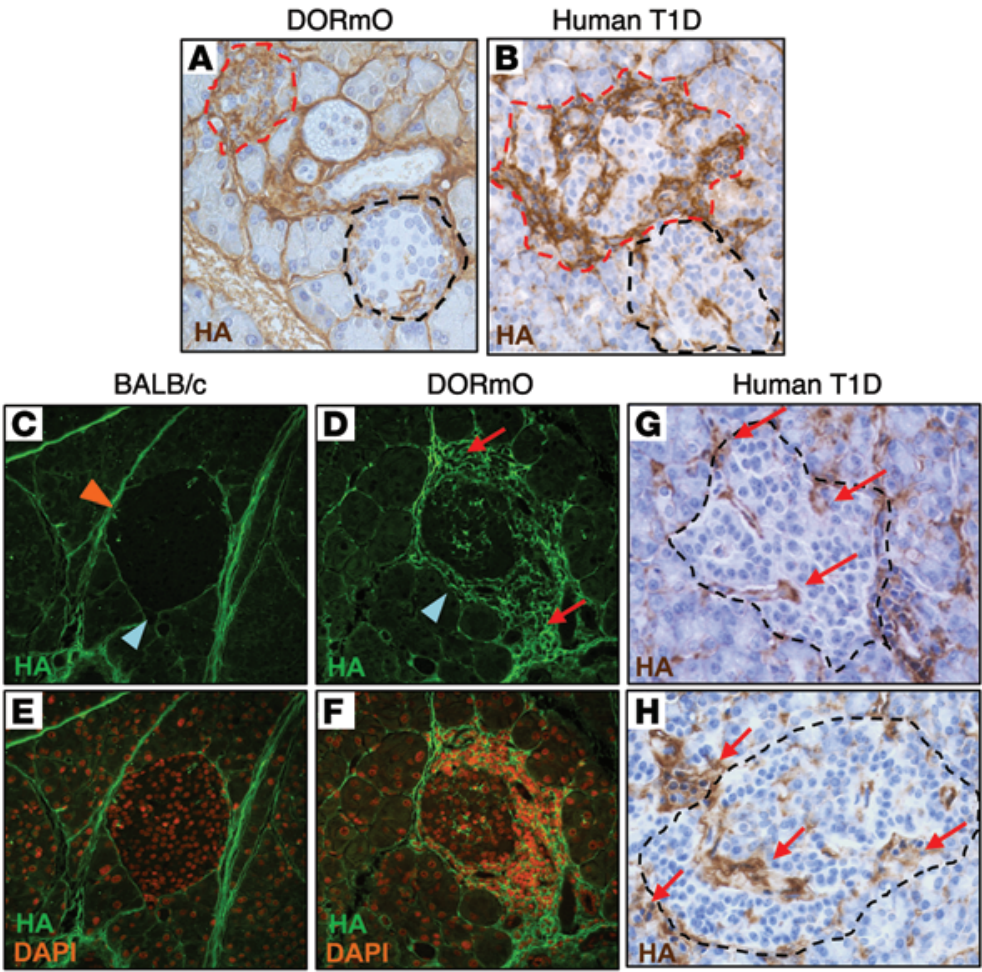

Figure 3. HA deposits characterize sites of insulitis in DORmO and human T1D. (A and $\mathbf{B}) \mathrm{HA}$ staining in pancreatic tissue isolated from (A) a DORmO mouse and (B) a human cadaveric donor with T1D. Infiltrated islets are circled in red; unaffected islets are circled in black. (C and D) HA staining of representative BALB/C and DORmO islets, demonstrating interstitial (orange arrowhead) and peri-islet (blue arrowheads) patterns of HA distribution. HA associated with lymphocytic infiltrates (red arrows) was only seen in DORmO mice. (E and $\mathbf{F}$ ) Costaining of HA and DAPI, demonstrating HA accumulation in association with insulitis. ( $\mathbf{G}$ and $\mathbf{H}$ ) HA deposits in human insulitis (red arrows) from two cadaveric donors with T1D. Original magnification, $\times 40$.

measured by intraperitoneal glucose tolerance testing (IPGTT) (Figure 5, C and D). Further, we asked whether mice rendered diabetic via STZ treatment had improved glycemic control on 4-MU, and they did not (Figure 5, E and F). Thus, these data did not support the hypothesis that 4-MU promoted regeneration of $\beta$ cells or improved metabolic control of hyperglycemia. Instead, these data suggested that 4-MU treatment suspended the progressive deterioration of insulin production otherwise observed in DORmO mice and that this effect was predicated upon the presence of viable $\beta$ cells.

4-MU treatment establishes regulatory checkpoints in insulitis. By 15 weeks of age, insulin-producing $\beta$ cells were characteristically lost in DORmO mice (Figure 6, A and B). However, in DORmO mice fed 4-MU, insulin staining was preserved (Figure 6, C-E), consistent with these mice remaining normoglycemic (Supplemental Figure 5A).

Robust insulitis was nonetheless still evident in 4-MU-treated DORmO mice (Figure 6, F and G). This effect was uniform across nearly all the islets that we examined. This nondestructive, "respectful" insulitis persisted while mice were maintained on 4-MU.

These effects were not associated with generalized immunosuppression. We observed a reduction in total splenocyte counts but unchanged lymphocyte counts in pancreatic lymph nodes (PLNs), mesenteric lymph nodes (MLNs), or inguinal lymph nodes (ILNs) (Supplemental Figure 5B). Proliferation of spleno- cytes in response to OVA peptide ex vivo was intact (Supplemental Figure 5C), and 4-MU-treated mice did not have reduced percentages of $\mathrm{CD}^{+} \mathrm{T}$ cells (Supplemental Figure 5D) or CD19+ B cells (Supplemental Figure 5E). Moreover, lymphocytes remained primed to destroy $\beta$ cells, as evidenced by the persistent insulitis (Figure 6, $\mathrm{F}$ and $\mathrm{G}$ ) and the rapid ( $<2$ week) progression to diabetes that we observed after cessation of 4-MU treatment. Overall, the evidence was not consistent with generalized immune suppression.

We considered whether 4-MU treatment prevented autoimmunity through impaired leukocyte trafficking. However, the histologic data from 4-week-old mice (Figure 1P) indicated that lymphocytosis was typically already established prior to initiation of 4-MU at 8 weeks of age.

4-MU treatment promotes FOXP3 induction in vitro and in vivo. The reestablishment of the "respectful" insulitis that we observed upon histologic staining led us to wonder whether 4-MU treatment might promote peripheral immune tolerance. One major source of immune tolerance is $\mathrm{FOXP}^{+}$Tregs.

We indeed observed that the percentage of $\mathrm{T}$ cells expressing the Treg marker FOXP3 was increased in islets of DORmO mice after treatment with 4-MU (Figure 7). Along with this increase in Tregs in insulitis, we observed a nonsignificant increase in $\mathrm{FOXP}^{+}$Tregs in the spleens, ILNs, PLNs, and MLNs (Supplemental Figure $5 \mathrm{~F}$ ). Together, these data suggested that 4-MU treatment promoted an increase in Tregs in insulitis.

To evaluate this possibility in the absence of hyperglycemia or other complicating factors, we examined Treg induction upon 4-MU treatment in a pair of in vivo mouse models. First, we assessed the impact of 4-MU on the percentage of GFP/FOXP3 ${ }^{+}$Tregs in total $\mathrm{CD}^{+}{ }^{+} \mathrm{T}$ cells in $\mathrm{BALB} / \mathrm{c}$ mice fed 4-MU or control chow for 2 weeks. We observed increased proportions of Tregs among $\mathrm{CD}^{+} \mathrm{T}$ cells in the spleens, ILNs, MLNs, and PLNs of the 4-MU-treated animals (Figure 8A) but no change in the total percentage of T cells (Supplemental Figure 6A). Similarly, the percentage of $\mathrm{CD}^{+} 9^{+} \mathrm{B}$ cells (Supplemental Figure 6B), $\mathrm{CD}^{2} 6^{+} \mathrm{CD} 19^{+} \mathrm{MHC}-\mathrm{II}^{+}$antigen-presenting cells (Supplemental Figure $6 \mathrm{C}$ ), and activated $\mathrm{CD} 44^{\mathrm{hi}} \mathrm{CD} 4^{+} \mathrm{T}$ cells (Supplemental Figure 6D) was not altered.

To test whether 4-MU could alter the peripheral development of Tregs, we then examined the induction of Tregs upon transfer of purified $\mathrm{CD}^{+} \mathrm{GFP}^{-}$(FOXP3 ${ }^{-}$) $\mathrm{T}$ cells into RAG-deficient animals in the setting of 4-MU or control chow. We found that 4-MU treatment enhanced the fraction of GFP/FOXP $3^{+}$Tregs observed 4 days after transfer (Figure 8B). Together, these results indicated that 4-MU enhances the peripheral differentiation of Tregs.

$H A$ and CD44 suppress FOXP3 induction. Because 4-MU, an inhibitor of HA synthesis, promotes FOXP3 levels, we asked whether HA and the HA receptor CD44 inhibit FOXP3 induction. Indeed, we observed that plate-coated HA and anti-CD44 antibody both diminished FOXP3 induction from $\mathrm{CD}_{4}^{+} \mathrm{GFP} / \mathrm{FOXP}^{-}$ precursors (Figure 8, C and D).

To better assess the contribution of CD44 to Treg induction, we then performed Treg induction using $\mathrm{CD}^{+}{ }^{+} \mathrm{GFP} / \mathrm{FOXP}^{-} \mathrm{T}$ 

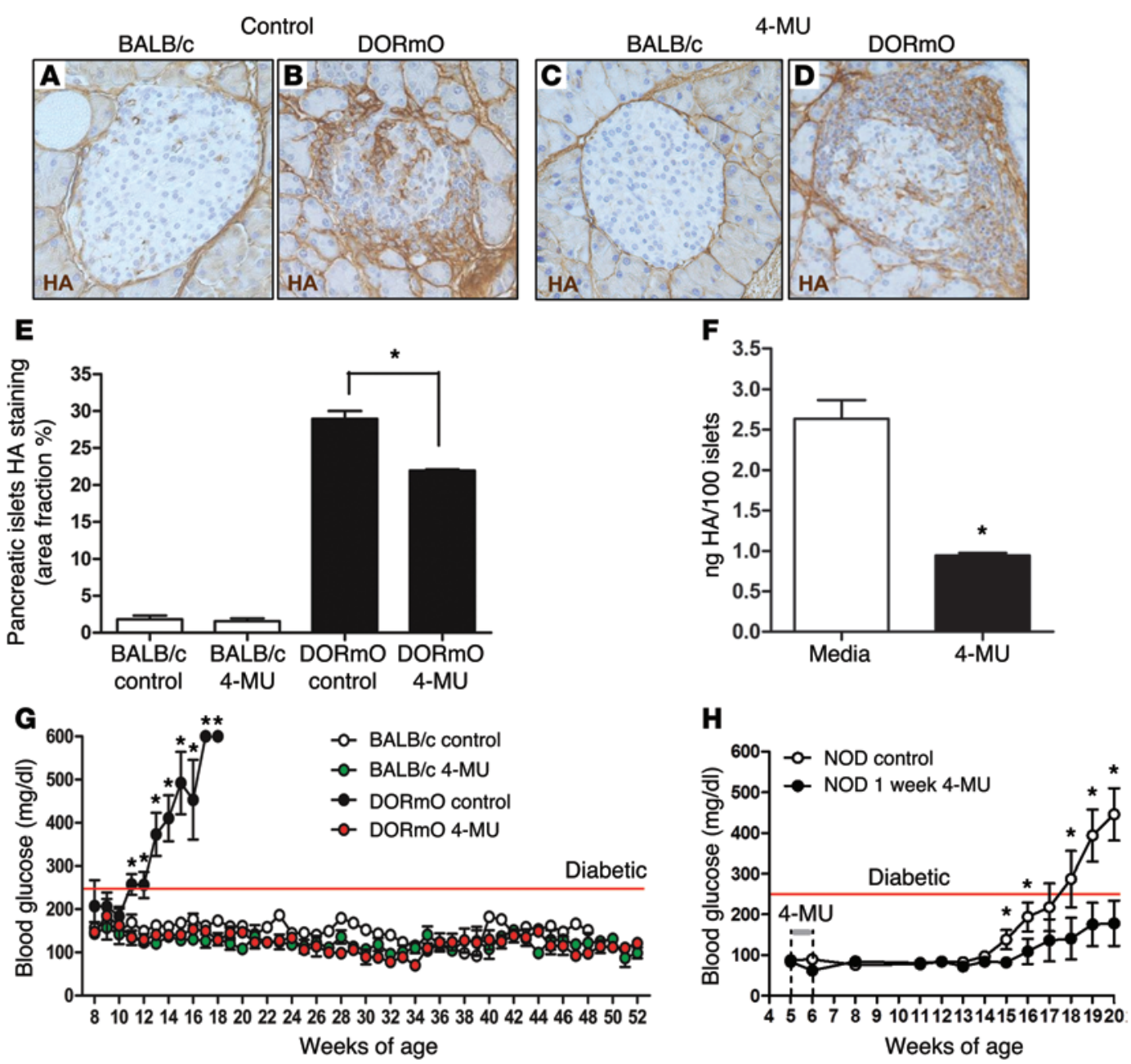

Figure 4. Inhibition of HA synthesis prevents progression to autoimmune diabetes. (A-D) Representative HA staining of pancreatic tissue from BALB/C (control) and DORmO mice fed 4-MU chow or control chow, beginning at 8 weeks of age, a month after the typical onset of insulitis in this model. (E) Average islet $\mathrm{HA}^{+}$area in these same mice. 25 islets were visualized per mouse, and staining and data are for 6 mice per condition. (F) $\mathrm{HA}$ content in islets from $\mathrm{BALB} / \mathrm{c}$ mice cultured with $50 \mu \mathrm{g} / \mathrm{ml}$ 4-MU or media alone. Data are for 100 islets, and experiments were done in triplicate. (G) Blood glucose of DORmO and BALB/C (control) mice fed 4-MU chow or control chow, beginning at 8 weeks of age, and maintained on 4-MU for 1 year ( $n=12$ mice per group). (H) Blood glucose of NOD mice fed with control chow or fed with control chow including a 1 week of 4-MU treatment from 5 to 6 weeks of age ( $n=10$ mice per group). Original magnification, $\times 40$. Data represent mean $\pm \mathrm{SEM} ;{ }^{*} P<0.05 \mathrm{vs}$. respective control and control for each time point by unpaired $t$ test.

cells isolated from $\mathrm{Cd} 44^{+/+}, \mathrm{Cd} 44^{+/}$, or $\mathrm{Cd} 44^{-/-}$mice as precursors. $\mathrm{T}$ cells from $\mathrm{Cd} 44^{-/}$mice had the greatest FOXP3 induction, with cells from heterozygous $\mathrm{Cd} 44^{+/-}$mice and homozygous $\mathrm{Cd} 44^{+/+}$ mice exhibiting less FOXP3 induction in inverse proportion to the number of $\mathrm{CD}_{4} 4^{+}$alleles they possessed (Figure 8, E and F).

To assess the impact of CD44 on Treg induction in vivo, we then performed a cotransfer of equivalent numbers of GFP/FOXP3 $\mathrm{CD}^{+}{ }^{+} \mathrm{Cd} 44^{+/+} \mathrm{CD} 45.1$ and $\mathrm{GFP} / \mathrm{FOXP} 3{ }^{-} \mathrm{CD} 44^{+} \mathrm{C} d 44^{-/-\mathrm{CD}} 45.2 \mathrm{~T}$ cells into $\mathrm{Rag}^{-/}$hosts. After 4 days, the numbers of $\mathrm{CD}^{+} \mathrm{GFP} / \mathrm{FOXP} 3^{+}$ cells and the ratio of $\mathrm{Cd} 44^{-/}(\mathrm{CD} 45.2)$ vs. $\mathrm{Cd} 44^{+/+}(\mathrm{CD} 45.1)$ Tregs were assessed. We found that $\mathrm{Cd} 44^{-/}(\mathrm{CD} 45.2)$ Tregs represent the majority of these cells in vivo (Figure 8G).

In light of these data, we were initially surprised when we observed that $\mathrm{Cd} 44^{-/}$mice did not naturally have increased numbers of CD4 $4^{+} \mathrm{GFP} / \mathrm{FOXP}^{+}$Tregs (Supplemental Figure 7A). However, spleens from $\mathrm{Cd} 44^{-/}$mice had significantly greater total numbers of $\mathrm{CD}^{+} \mathrm{T}$ cells (Supplemental Figure 7B), and $\mathrm{CD} 4^{+}$ $\mathrm{T}$ cells from these animals had a hyperproliferative response to
anti-CD3/28 antibody activation (Supplemental Figure 7C). Both of these findings have been reported previously and attributed to defects in activation-induced cell death pathways (22). The absolute numbers of splenic $\mathrm{CD} 4^{+} \mathrm{GFP} / \mathrm{FOXP3}^{+}$Tregs were actually higher on average in $\mathrm{Cd} 44^{-/}$mice, although this trend did not reach statistical significance (Supplemental Figure 7D). Together, these data are consistent with an increased generation of Tregs in $\mathrm{Cd} 44^{-/}$mice but suggest that this effect was obscured by heightened proliferation of effector $\mathrm{T}$ cells in these same animals.

Inhibition of ERK1/2 signaling partially overcomes CD44-mediated inhibition of FOXP3. We observed that the inhibitory effects of anti-CD44 antibody on FOXP3 induction enhanced anti-CD28 antibody-mediated FOXP3 inhibition (Figure 9, A and B), an effect known to proceed through AKT signaling (23). These data suggested that CD44 signaling might inhibit FOXP3 induction via pathways in addition to or other than AKT.

One signaling pathway known to inhibit FOXP3 induction is ERK1/2 (24). We previously reported that, when using human 
A
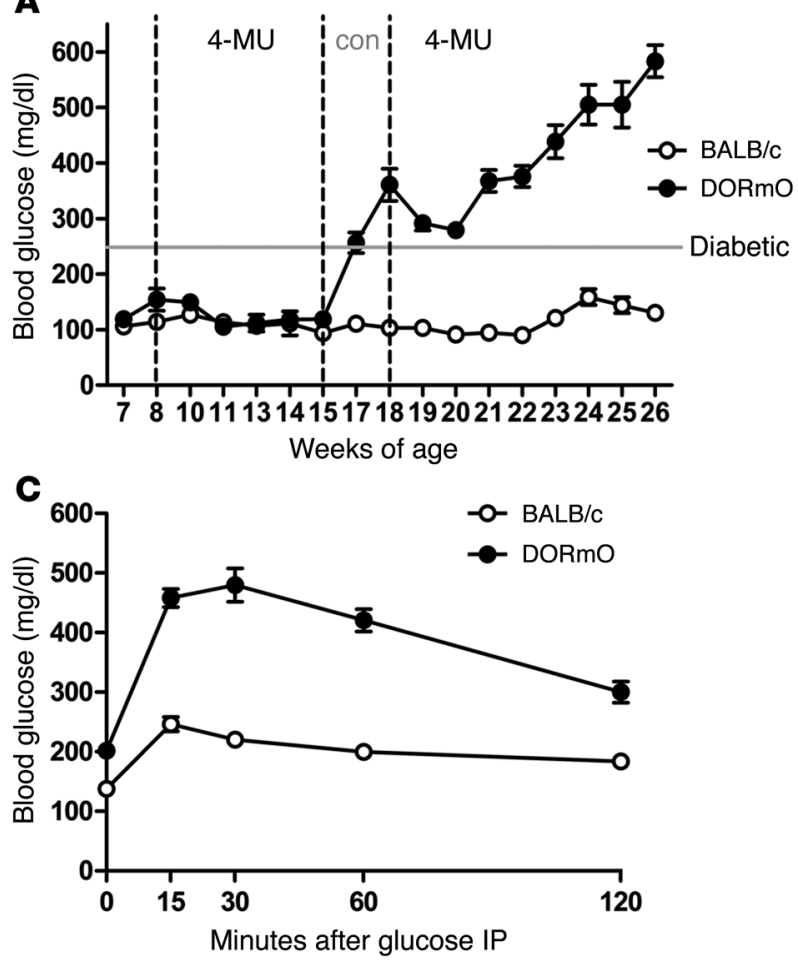

$\mathbf{E}$

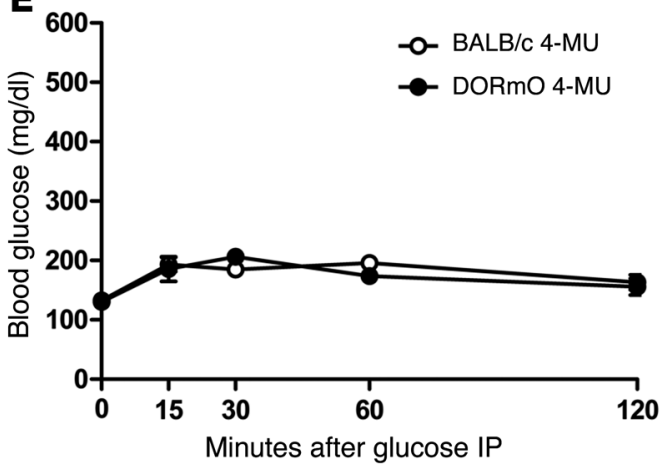

B
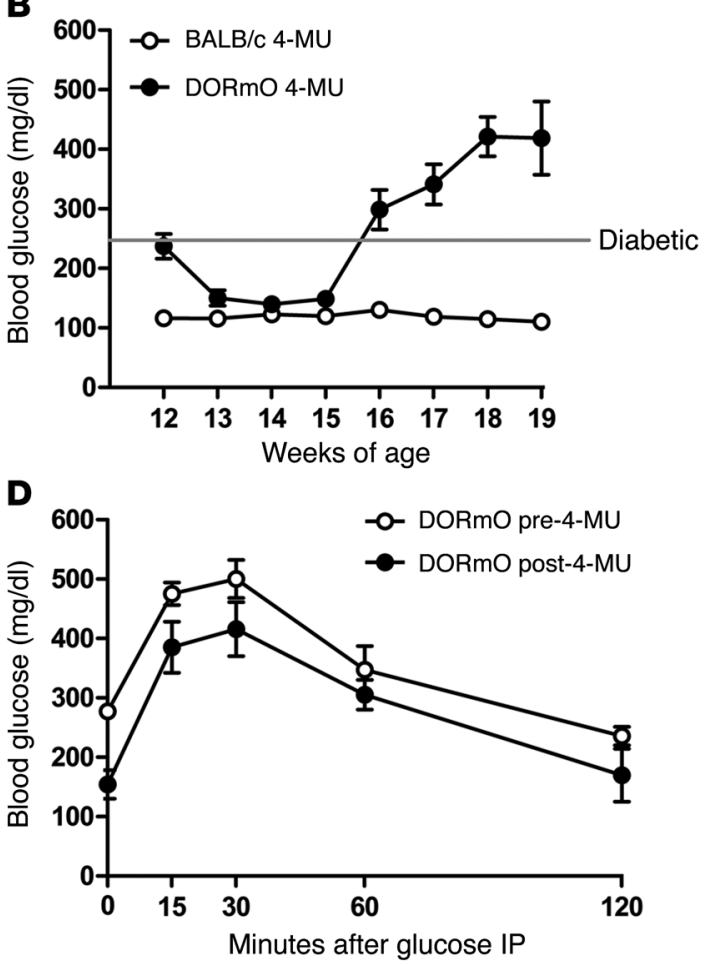

$\mathbf{F}$

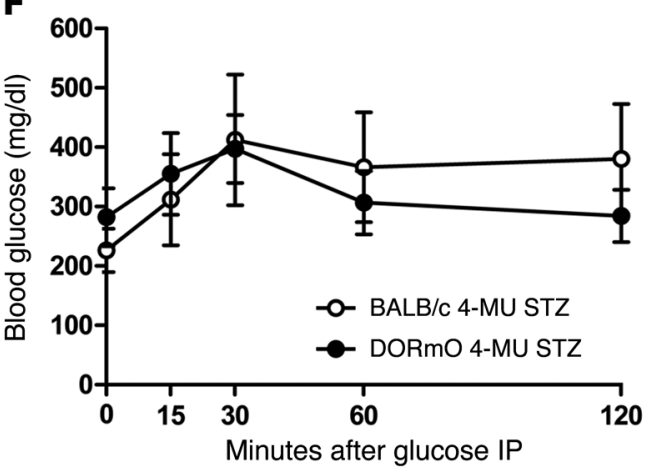

Figure 5. 4-MU treatment prevents progression of insulitis but does not cure established diabetes. (A) Blood glucose of DORmO and control mice started on 4-MU at 8 weeks of age, taken off 4-MU between 15 and 18 weeks of age, and restarted on 4-MU thereafter $(n=10)$. (B) Blood glucose of DORmO and $\mathrm{BALB} / \mathrm{c}$ (control) mice fed 4-MU chow, beginning at 12 weeks of age $(n=10)$. (C) Blood glucose following IPGTT for control chow-fed BALB/C and DORmO mice at 10 weeks of age ( $n=8$ mice per group). (D) Blood glucose following IPGTT of DORm0 mice from C treated for 2 weeks with 4-MU or control chow. (E) Blood glucose following IPGTT of BALB/c and DORmO mice at 10 weeks of age following 4-MU treatment for 2 weeks $(n=6)$. (F) Blood glucose following IPGTT for the same mice as in E, now made hyperglycemic by STZ treatment $(n=6)$. Data represent mean \pm SEM.

$\mathrm{T}$ cells, CD44 signaling promotes phosphorylation of ERK1/2 (pERK1/2) (25). In mouse $\mathrm{CD}^{+} \mathrm{T}$ cells we likewise found that CD44 crosslinking induced pERK1/2 (Figure 9C).

We then asked whether inhibition of pERK1/2 could restore the loss of FOXP3 induction we observed upon anti-CD44 antibody treatment. Using $\mathrm{CD} 4^{+} \mathrm{GFP} / \mathrm{FOXP}^{-} \mathrm{T}$ cells activated for 72 hours in the setting of TGF- $\beta$ and IL-2, we found that SUO126, an ERK1/2 inhibitor, could overcome the inhibition of FOXP3 induction with or without CD44 costimulation (Figure 9, D and E).

Finally, we asked whether infiltrating lymphocytes express $\mathrm{CD} 44$. We indeed observed an increase in $\mathrm{CD}_{4} 4^{+}$staining during insulitis progression (Figure 9, F-L), suggesting that cells present in insulitis may be responsive to local HA.
Together, these data implicate a role for CD44 and HA in inhibition of Treg differentiation and support the hypothesis that 4-MU treatment relieves this inhibition by reducing HA-mediated CD44 signaling.

\section{Discussion}

We have identified a critical role for HA in the pathogenesis of autoimmune diabetes. We observed that HA deposits are both temporally and anatomically associated with autoimmune insulitis in both T1D and in the DORmO mouse model of the disease. Both the amount and distribution of HA closely tracked with the infiltration of $\mathrm{CD}^{+} \mathrm{T}$ cells and the disappearance of insulin staining. HA was not increased within neighboring islets without active insulitis. 

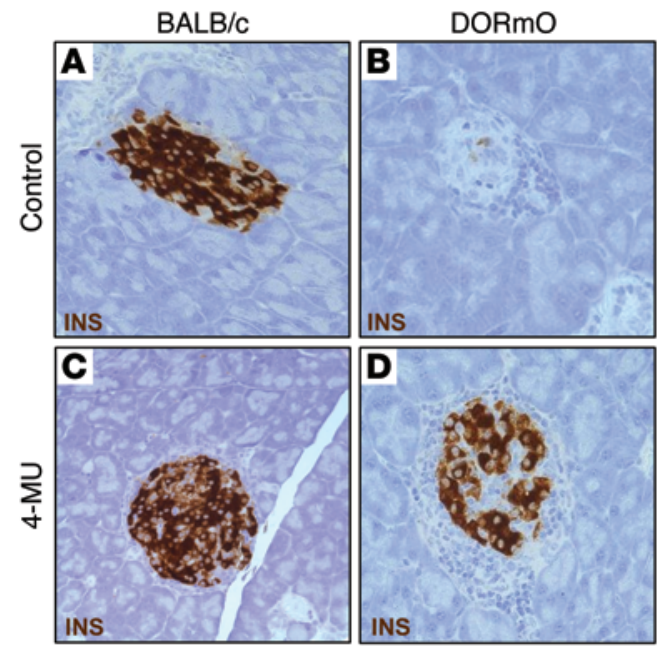

E
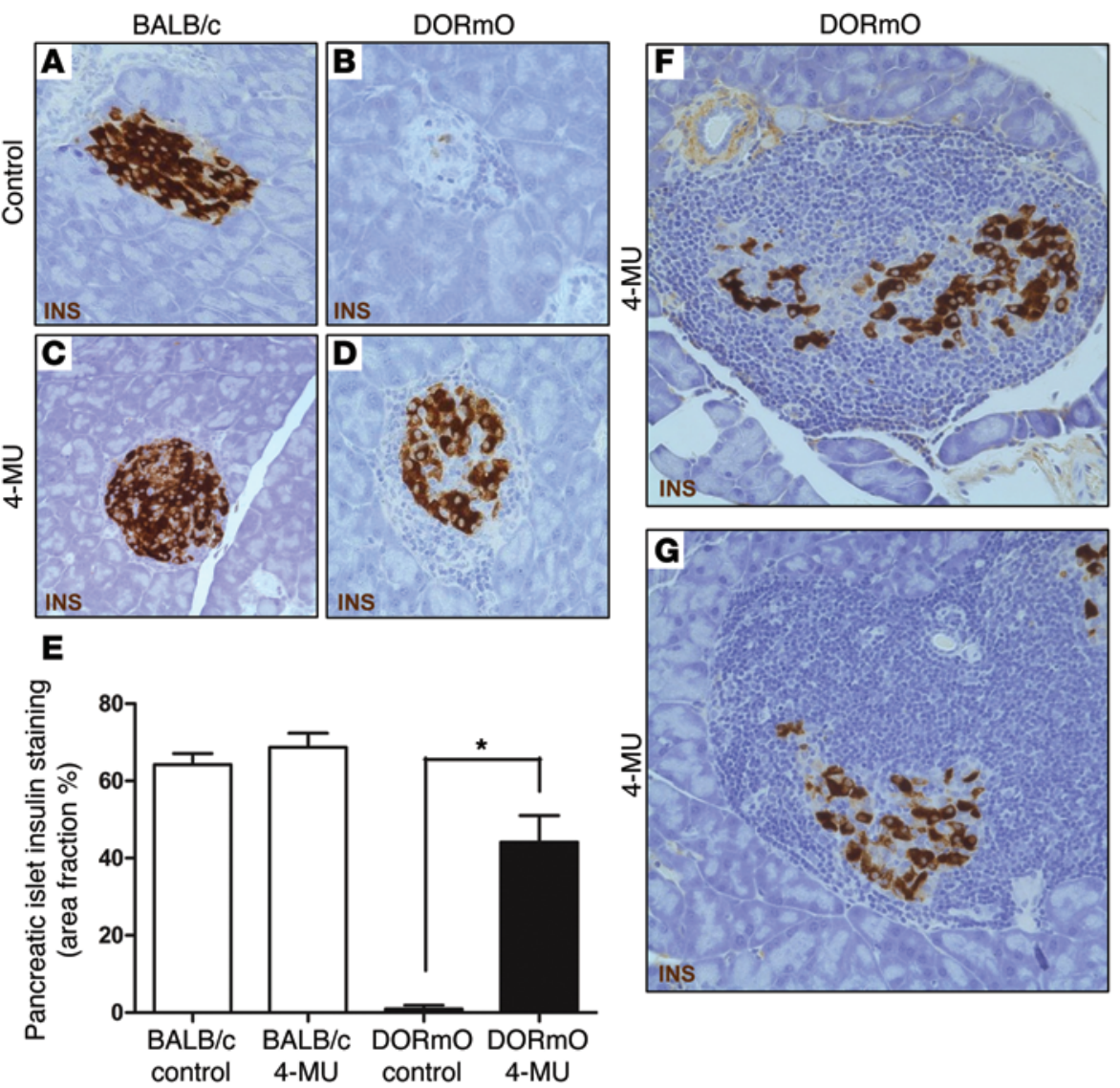

Figure 6. 4-MU treatment promotes nondestructive insulitis. (A-D) Insulin staining of representative pancreatic tissue sections from DORmO and BALB/C mice fed either 4-MU or control chow. (E) Average insulin ${ }^{+}$area of islets for these mice. 25 islets were visualized per mouse, and staining and data are for 6 mice per condition. (F and $\mathbf{G}$ ) Representative images of insulin staining of pancreatic islets from 15 -week-old DORm0 mice treated with $4-\mathrm{MU}$ for 7 weeks. Original magnification, $\times 40$. Data represent mean $\pm \mathrm{SEM} ;{ }^{*} P<0.05$ vs. respective control by unpaired $t$ test.

Further, inhibition of HA synthesis using 4-MU prevented diabetes and preserved insulin content within islets in DORmO mice, despite ongoing, robust lymphocytic infiltrates. These effects were stable while mice were on continuous treatment for over a year. Of note, this treatment was initiated when the mice were 8 weeks of age, at which time insulitis is typically well established in DORmO mice. This is a strong, protective phenotype in a model in which the incidence of autoimmune diabetes is typically $100 \%$ (13). Furthermore, a short 1-week course of 4-MU treatment was sufficient to prevent diabetes progression in the canonical mouse model of T1D, the NOD mouse. We conclude from these data that HA production is necessary for destructive insulitis and that 4-MU treatment can forestall progression to diabetes in multiple mouse models of T1D.

Our data indicate that HA suppressed $\mathrm{FOXP}^{+}$Treg induction. Both $\mathrm{HA}$ and antibodies directed at the $\mathrm{HA}$ receptor, CD44, inhibited induction of $\mathrm{FOXP}^{+}$Tregs from $\mathrm{CD}^{+} \mathrm{GFP} / \mathrm{FOXP}^{-}$precursors. Conversely, this inhibition was relieved by inhibition of HA synthesis with 4-MU. Together with our earlier work $(26,27)$, these data suggest that CD44 restricts the expansion of Tregs but promotes their phenotypic stability. This is the inverse of TLR2 agonists, which are known to promote Treg induction but inhibit suppression $(28,29)$.
This HA- and CD44-mediated inhibition of FOXP3 induction was dependent on ERK1/2 signaling. This is consistent with a previous report that ERK1/2 inhibition promotes FOXP3 induction (24). However, these data do not preclude a role for other pathways. For example, CD44 also promotes signaling through AKT, which is also known to inhibit FOXP3 differentiation (23).

In light of these data, we propose a model whereby the inappropriate accumulation of HA at sites of chronic inflammation creates an environment permissive to autoimmunity by restricting Treg differentiation. Moreover, we postulate that clearance of HA upon the resolution of inflammation (or 4-MU treatment) may reestablish a regulatory checkpoint by allowing Treg differentiation and, thereby, increasing the ratio of FOXP3 ${ }^{+}$Tregs to $\mathrm{T}$ effector cells. This ratio is known to be critical in enforcing peripheral tolerance (30), and Tregs are known to play a critical role in protection from autoimmune diabetes in both human T1D (1) and mouse models of the disease (31). This model may help explain how tissue factors influence local Treg numbers and function in autoimmune insulitis (3-5). However, these data do not preclude effects of 4-MU on other cell types. HA has varied roles in tissue structure and function that may also be affected by 4 -MU.

The impact of HA on local immune regulation may also be influenced by the local organization of HA in vivo. We observed decreases in the hyaladherins TSG6 and I $\alpha$ I during the progression to T1D. Because these molecules regulate HA binding to CD44, they may affect the phenotypes associated with HA (32). Other components of the ECM are also reported to contribute to the development and progression of insulitis, either through HA-dependent or -independent mechanisms (6, 33-37). Taken together with our recent work on HA in human T1D (6), the progression to autoimmune diabetes is associated with profound changes in the ECM architecture.

It is notable that substantial intraislet HA deposits persisted, despite 4-MU treatment. Since 4-MU works at the level of HA synthesis (rather than clearance or catabolism), we suspect that it may take time for HA at sites of inflammation to disappear. The fact that $\beta$ cell destruction is nonetheless forestalled suggests that 4-MU may also induce qualitative changes in resulting ECM that influence local immune function. Histologic assessments may also understate the HA decrease because they measure the area within which HA is deposited and not the quantity of HA there. This is perhaps evident in the difference between the decrease in HA area measured histologically (>25\%; Figure 


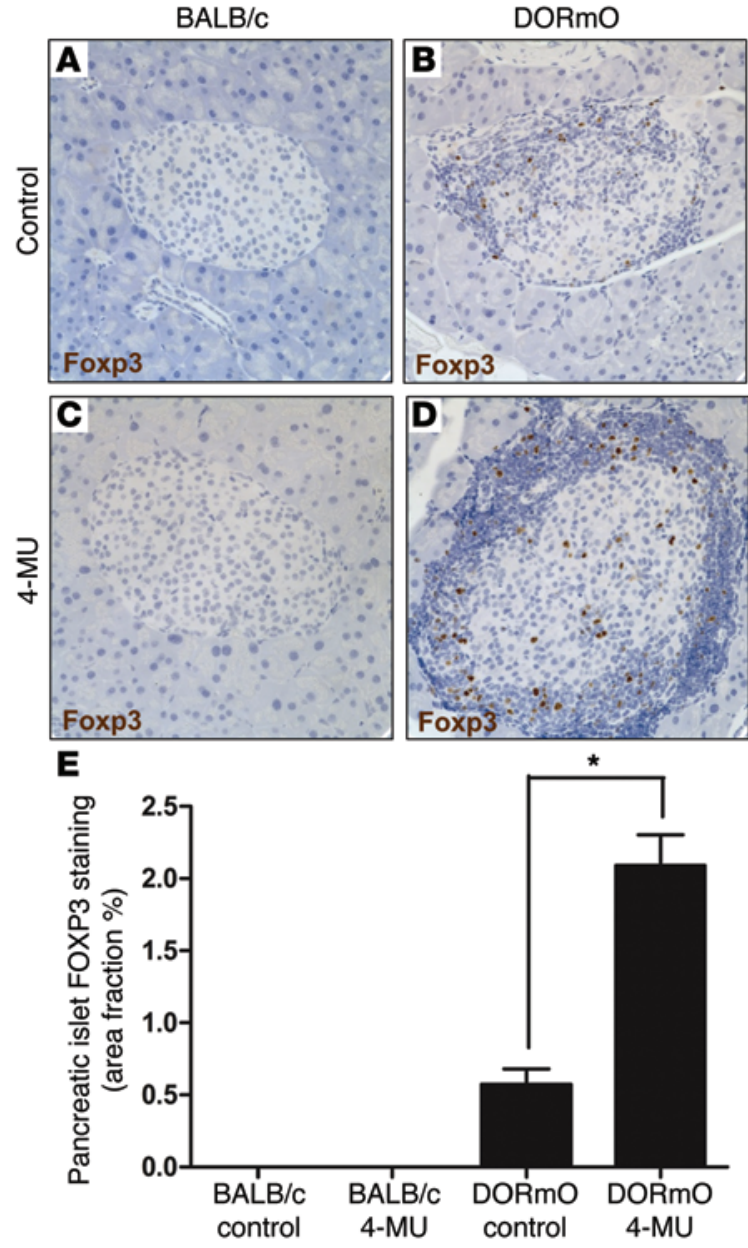

$4 \mathrm{E})$ and the drop in HA content in 4-MU-treated islets measured biochemically $(>60 \%$; Figure $4 \mathrm{~F})$, although these data are from different experiments.

These data may also help explain reports that 4-MU reduces inflammation. 4-MU has been mostly used in animal models to prevent tumor metastasis, in which HA is thought to drive angiogenesis and tumor proliferation (38-40). A handful of reports suggest that 4-MU may also have utility in other inflammatory settings $(9,41)$. However, to our knowledge, insight into the relevant immunologic mechanisms is limited to two studies. One study reported that 4-MU treatment reduced MMP expression in a mouse model of collagen-induced arthritis (42). Another recent report suggested that 4-MU increased spinal cord expression of CXCL12 and decreased Th1 responses, while increasing numbers of Tregs (43). Here, we established that HA inhibits FOXP3 expression via a CD44- and ERK1/2-dependent pathway, that 4 -MU promotes Treg numbers via increased differentiation, and that these Tregs constrained effector $\mathrm{T}$ cells at the site of autoimmunity. Further, we have demonstrated that 4-MU works in the setting of established autoimmunity (analogous to how it would actually be used in people), that it can be used as a chronic therapy, and that it can be used to treat autoimmune diabetes. These data should greatly facilitate the clinical translation of 4-MU.

These data are particularly exciting because 4-MU is already an approved drug. Called "hymecromone," it is used through-
Figure 7. 4-MU treatment increases islet FOXP3+ Tregs. (A-D) FOXP3 staining of representative pancreatic tissue sections from $D O R m O$ and $\mathrm{BALB} / \mathrm{c}$ mice fed either 4-MU or control chow. (E) Average FOXP3+ islet area of these mice. At least 25 islets were visualized per mouse, and data are for 6 mice per condition. Original magnification, $\times 40$. Data represent mean \pm SEM; ${ }^{*} P<0.05$ vs. respective control by unpaired $t$ test.

out Europe and Asia to treat biliary spasm $(44,45)$. It is an orally available agent that has been used for over 30 years in both adults and children. Because of this established track record and favorable side effect profile, 4-MU may be uniquely appropriate as a therapy for T1D.

It is noteworthy that 4-MU treatment did not restore normoglycemia to STZ-treated mice or to DORmO mice when it was initiated at 12 weeks of age or later. Additionally, 4-MU treatment did not appear to promote islet regeneration. This suggests that residual populations of viable $\beta$ cells are required for $4-\mathrm{MU}$ effects. Moreover, autoimmune diabetes developed rapidly upon cessation of the drug, suggesting that long-term therapy may be necessary.

In summary, our data indicate that the local accumulation of HA follows the temporal and geographic progression of autoimmune insulitis in this model. Moreover, inhibition of HA synthesis promotes $\mathrm{FOXP}^{+}$Treg induction via a CD44and ERK1/2-dependent pathway and prevents progression of $\beta$ cell destruction. In light of these data, we propose that hymecromone (4-MU) treatment, alone or following a tolerance induction regimen (46), may have great potential as a maintenance agent to prevent T1D progression in at-risk, autoantibody-positive individuals who still retain some level of endogenous insulin production.

\section{Methods}

Mice. All animals were bred and maintained under specific pathogenfree conditions, with free access to food and water, in the vivarium at the Benaroya Research Institute and the animal facilities at Stanford University Medical School (Stanford, California, USA). DO11.10 transgenic mice were purchased from The Jackson Laboratory (JAX) and bred with $\mathrm{BALB} / \mathrm{c}$ mice expressing RIPmOva (available at the Benaroya Research Institute) to generate the DORmO double-transgenic mice. NOD mice were purchased from JAX. Foxp3-GFP C57BL/6 mice were a gift from Alexander Rudensky (Memorial Sloan Kettering, New York, New York, USA). CD44-deficient C57BL/6 (Cd44--/) mice were purchased from JAX and intercrossed with Foxp3-GFP mice to generate Foxp3-GFP Cd44-- mice.

Human tissues. We used cadaveric pancreatic tissue sections from donors with T1D. These were obtained through the JDRF-sponsored nPOD program. Case numbers cited herein were assigned by nPOD unless otherwise noted. Demographic attributes of these donors and detailed histopathological characterization of their tissue samples have been previously described (6). All the tissues showed well-preserved morphology without any evidence of autolysis.

4-MU treatment. The 4-MU (Alfa Aesar) was pressed into the mouse chow by TestDiet and irradiated before shipment, as previously described (20). We previously determined that this chow formulation delivers $250 \mathrm{mg} / \mathrm{mouse} / \mathrm{d}$, yielding a plasma drug concentration of $640.3 \pm 17.2 \mathrm{nmol} / \mathrm{l}$ in mice, as measured by HPLC-MS. 

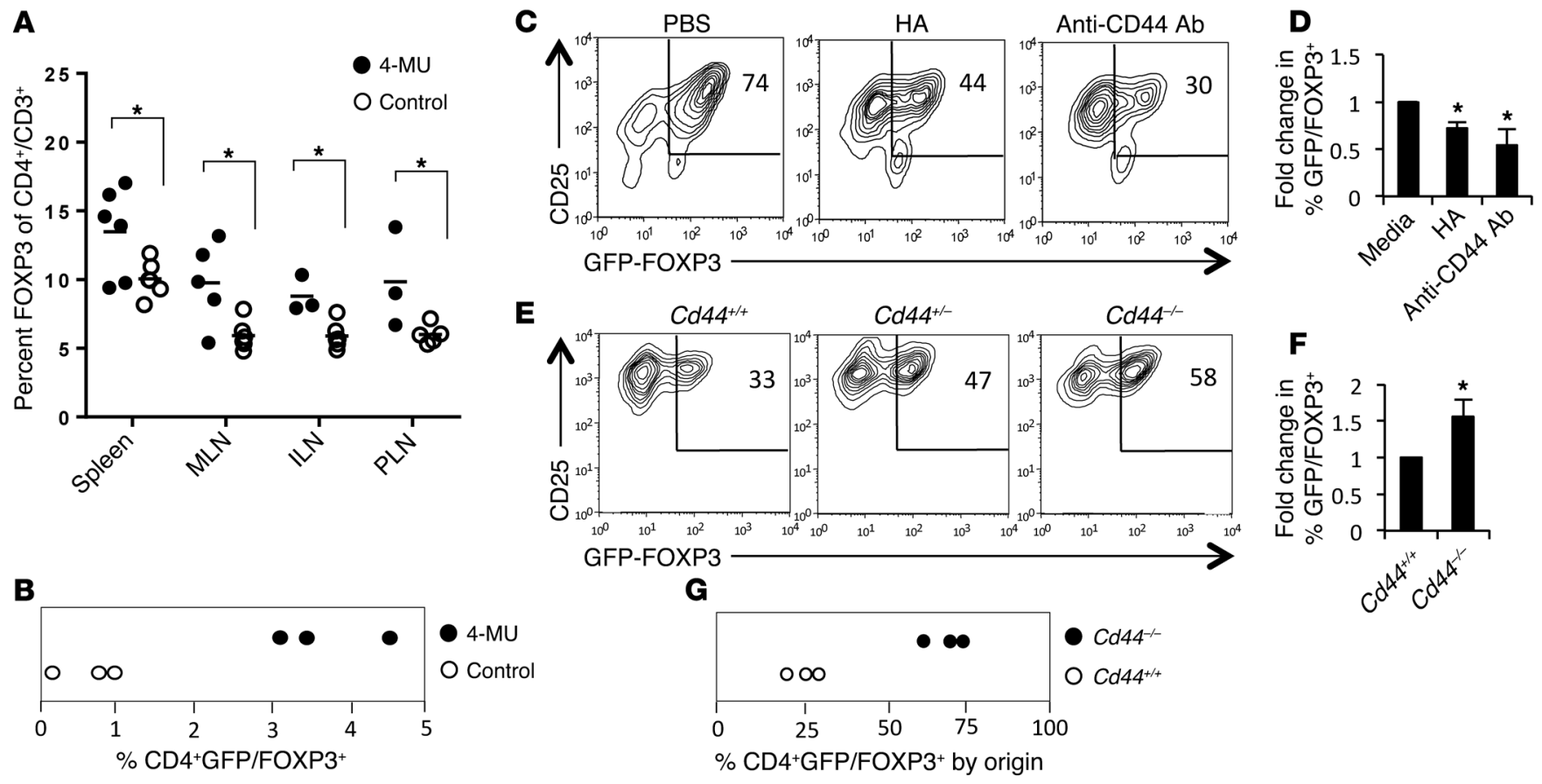

Figure 8. 4-MU treatment relieves CD44-mediated inhibition of FOXP3 induction. (A) Percentage of GFP/FOXP3 $3^{+}$Tregs of total CD4+ $T$ cells in BALB/C mice fed 4-MU or control chow for 2 weeks ( $n=5-6$ mice per group). (B) In vivo induction of FOXP3 ${ }^{+}$Tregs assessed 4 days after transfer of GFP/ FOXP3-CD4+ T cells into $\mathrm{Rag}^{-/-}$hosts given 4-MU or control chow ( $n=3 \mathrm{Rag}^{-/-}$recipient animals). Data are from the spleens of recipient animals. (C) CD25 and FOXP3 expression by CD4+GFP/FOXP3- T cells activated for 72 hours with or without plate-bound HA or anti-CD44 antibody. (D) Pooled data for 3 independent experimental replicates for the representative data in C. (E) FOXP3 induction using $C d 44^{+/+}, C_{4} 44^{-/+}$, or $C d 44^{-/-}$precursors. (F) Pooled data for 3 independent experimental replicates for the representative data in $\mathbf{E}$. (G) In vivo induction of FOXP3 assessed using cotransfer of equivalent numbers of

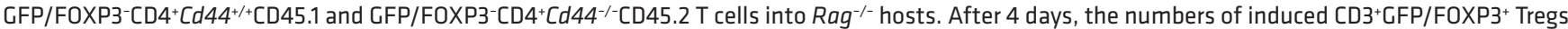
in the spleens of recipient animals were assessed and the ratio of $C d 44^{-/-}$Tregs versus $C d 44^{+/+}$Tregs was determined $\left(n=3\right.$ Rag ${ }^{-/-}$recipient animals). Data represent mean $\pm \mathrm{SEM} ;{ }^{*} P<0.05$ vs. respective control by unpaired $t$ test.

Unless otherwise noted, mice were initiated on the 4-MU chow at 5,8 , or 12 weeks of age and were maintained on this diet until they were euthanized.

Weight and diabetes monitoring. Beginning at 4 weeks of age, mice were weighed weekly as well as bled via the saphenous vein for the determination of their blood glucose level using a Contour blood glucose meter and blood glucose monitoring strips (Bayer Healthcare). When two consecutive blood glucose readings of $250 \mathrm{mg} / \mathrm{dl}$ were recorded, animals were considered diabetic. When two consecutive blood glucose readings of $300 \mathrm{mg} / \mathrm{dl}$ were recorded, animals were euthanized. For IPGTTs, mice were fasted (given water only) for 8 to 12 hours. Mice were then injected intraperitoneally with $1.0 \mathrm{mg} / \mathrm{ml}$ D-glucose (stock solution in PBS) at a dose of $1 \mathrm{~g} / \mathrm{kg}$ body weight. Saphenous blood glucose readings were taken at $0,15,30,60$, and 120 minutes after injection.

Flow cytometry and phenotyping. Mouse leukocyte populations were isolated from ILNs, MLNs, PLNs, and spleens as previously described (26). Mouse flow cytometry experiments used the following fluorochrome-labeled antibodies from BD Biosciences: CD3e (145-2C11), CD4 (RM4-5), CD25 (PC61.5), and CD44 (IM7). FOXP3 (FJK.16a) antibody and staining reagents from eBioscience were used as per the manufacturer's instructions. FACS samples were stained in media on ice for 45 minutes, washed once, resuspended in FACS stain buffer (PBS containing 1\% FBS, 0.1\% Na-azide), and run on a FACSCalibur flow cytometer (BD). Analysis was performed using CELLQuest (BD) and FlowJo (Treestar Inc.) software.
For intracellular phospho staining, freshly isolated $\mathrm{CD} 4{ }^{+} \mathrm{CD} 25^{-} \mathrm{T}$ cells were incubated with anti-CD 44 antibody $(10 \mu \mathrm{g} / \mathrm{ml})$ or an isotype control antibody for 20 minutes on ice. Following one wash, goat antimouse $\mathrm{F}\left(\mathrm{ab}^{\prime}\right) 2$ fragment $(20 \mu \mathrm{g} / \mathrm{ml})$ was added. Following incubation at $37^{\circ} \mathrm{C}$ for the indicated times, cells were fixed and stained for FACS analysis per the manufacturer's protocols using anti-phospho-ERK1/2 (pT202/pY204) (BD).

Isolation of leukocyte populations and Treg induction. $\mathrm{CD}^{+}$cells were isolated from splenocytes and lymphocytes using MACS Kits (Miltenyi Inc.), and the $\mathrm{GFP}^{-} \mathrm{FOXP}^{-}$fraction was isolated from the $\mathrm{CD}^{+}$population using a FACS Vantage cell sorter (BD Biosciences). $\mathrm{CD}^{+} / \mathrm{GFP}^{-} \mathrm{FOXP}^{-} \mathrm{T}$ cells were used to ensure that any FOXP3 induction we observed would be from conventional $\mathrm{T}$ cell progenitors. Cells were cultured in DMEM-10 (Invitrogen) supplemented with 10\% FBS (Hyclone, GE Healthcare), penicillin/streptomycin, $50 \mu \mathrm{M} \beta$-mercaptoethanol, $2 \mathrm{mM}$ glutamine, and $1 \mathrm{mM}$ Na pyruvate (Invitrogen).

The in vitro induction of $\mathrm{FOXP}^{+}{ }^{+}$Tregs from $\mathrm{CD}^{+}{ }^{+} \mathrm{FOXP}^{-}$precursors was done as described previously (27). In brief, cell culture plates (96 well) were coated with $5 \mu \mathrm{g} / \mathrm{ml}$ anti-CD3 antibody (145-2C11, BD Biosciences) and $2.5 \mu \mathrm{g} / \mathrm{ml}$ anti-CD28 antibody (37.51, BD Biosciences) unless otherwise noted. Where noted, plates were washed and then coated with $0.2 \mathrm{mg} / \mathrm{ml} \mathrm{BSA-conjugated} \mathrm{HA}\left(1.5 \times 10^{6} \mathrm{Da}\right)$ HA (Genzyme), $1 \mu \mathrm{g} / \mathrm{ml}$ anti-CD44 antibody (IM7, BD Biosciences), or $10 \%$ BSA. $\mathrm{CD}^{+} / \mathrm{GFP}^{-} \mathrm{FOXP}^{-} \mathrm{T}$ cells $\left(2 \times 10^{5}\right.$ per plate $)$ were cultured for 96 hours on these plates, followed by collection of the cells and culture supernatants for analysis. For Treg induction, $\mathrm{CD}^{+} / \mathrm{GFP}^{-}$ 
A
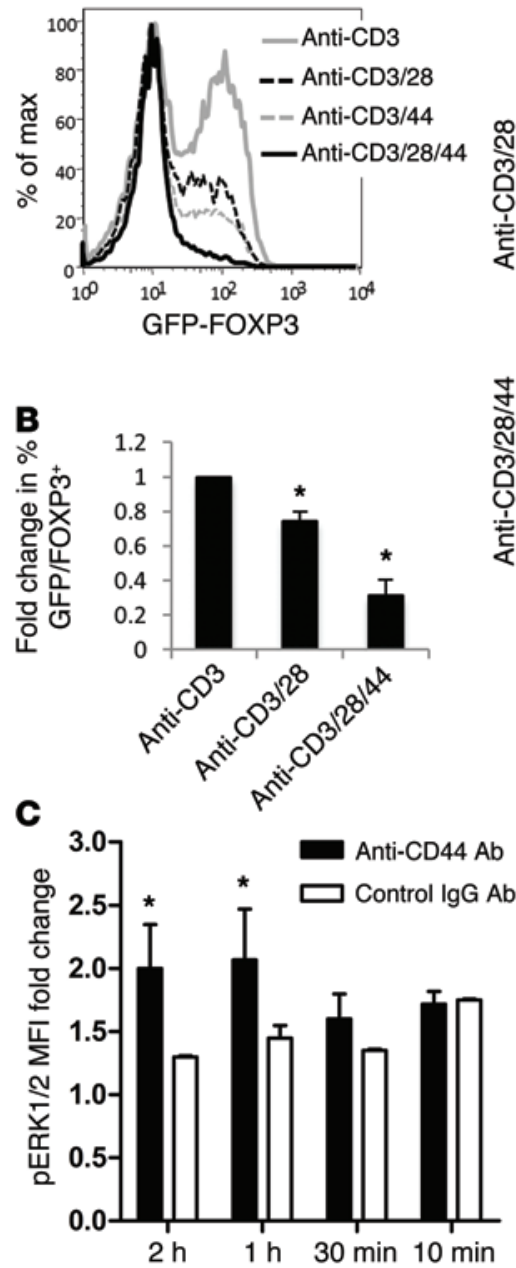

D

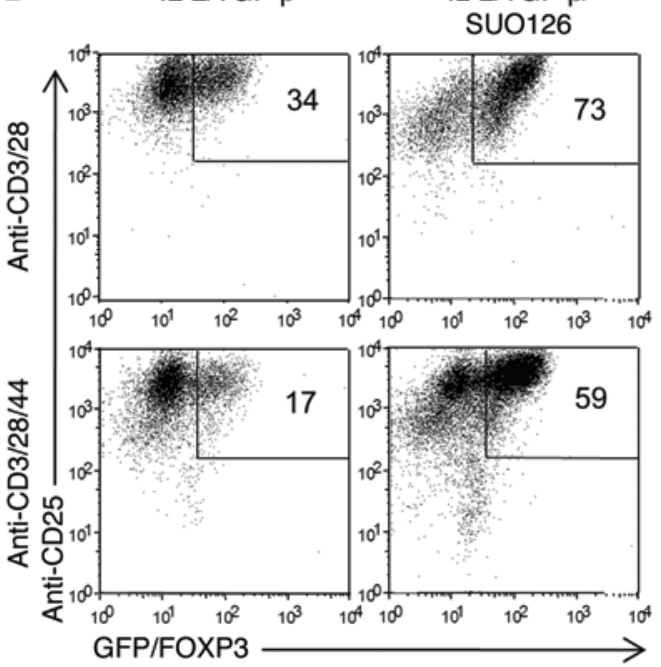

E

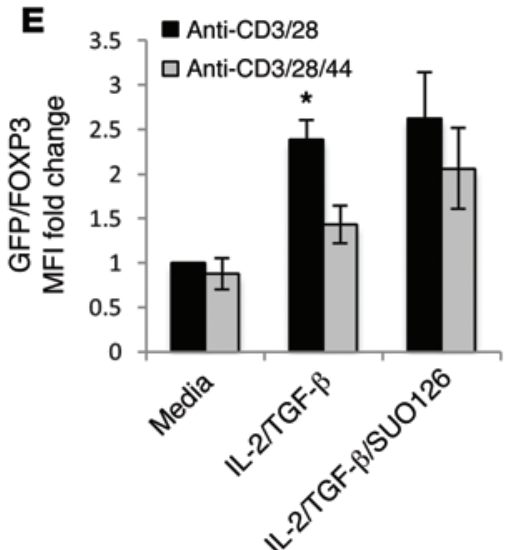

BALB/c
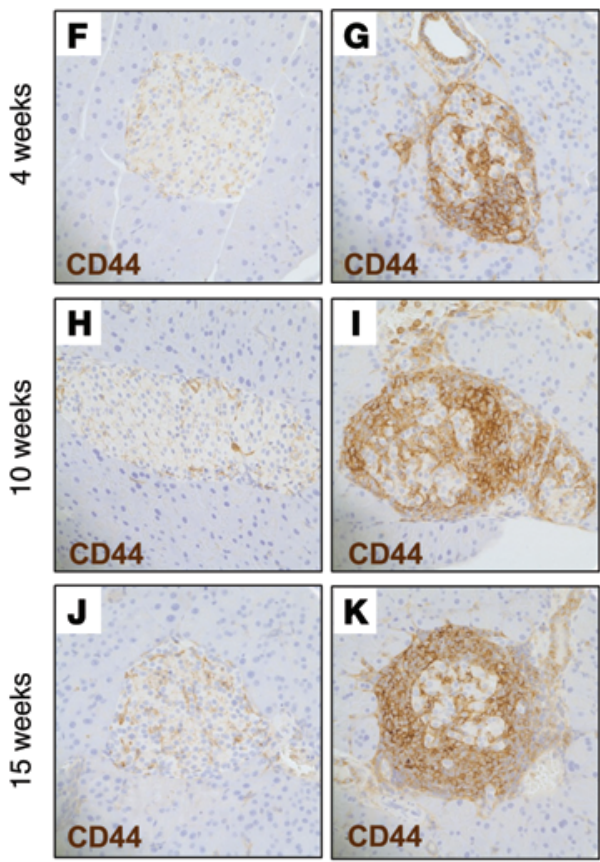

L

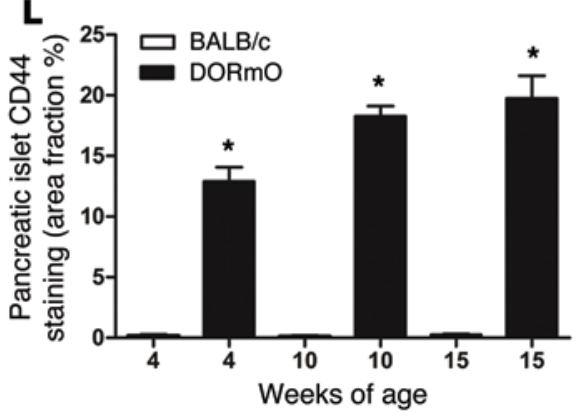

Figure 9. 4-MU treatment promotes FOXP3 induction. (A) FOXP3 levels following induction from CD4 ${ }^{+} \mathrm{CFP} / \mathrm{FOXP3^{- }}$ T cell precursors performed in the setting of anti-CD3, with or without anti-CD28 and/or anti-CD44 antibody costimulation. (B) Pooled data for 4 independent experimental replicates for the representative data in A. (C) Fold change in pERK1/2 MFI over time following CD44 crosslinking. The data shown incorporate 3 experimental replicates. (D) CD25 and GFP/FOXP3 levels following activation of CD4+CFP/FOXP3- T cells in the setting of TCF- $\beta$ and IL-2, with or without CD44 costimulation and/or the ERK1/2 inhibitor SU0126. (E) Pooled data for 6 independent experimental replicates for the representative data in D. (F-K) CD44 staining of representative pancreatic tissue sections from BALB/c (control) or DORm0 mice fed either 4-MU or control chow. (L) Average CD44+ area of islets for these mice. At least 25 islets were visualized per mouse $(n=6)$. Original magnification, $x 40$. Data represent mean \pm SEM; ${ }^{*} P<0.05$ vs. respective control and control for each time point by unpaired $t$ test.

FOXP3- $^{-} \mathrm{T}$ cells were cultured in the setting of $50 \mathrm{ng} / \mathrm{ml}$ TGF- $\beta$ and $100 \mathrm{IU} / \mathrm{ml} \mathrm{IL}-2$, both added at the inception of the experiment. GFP/ FOXP3 expression was assessed after 72 to 96 hours.

For the in vivo FOXP3 ${ }^{+}$Treg induction experiments, $\mathrm{CD}^{+} / \mathrm{GFP}^{-}$ FOXP3 $^{-} \mathrm{T}$ cells were isolated as described above. $1 \times 10^{6}$ of these cells were transferred into 6- to 8-week-old $\mathrm{Rag}^{-{ }^{--}}$mice purchased from JAX. The percentage of GFP/FOXP3 ${ }^{+}$Tregs among all $\mathrm{CD}^{+}{ }^{+}$splenocytes was assessed after 72 to 96 hours.

Islet isolation. Islets were isolated as described previously (47). Briefly, mice at 8 weeks of age were anesthetized with 2,2,2-tribromoethanol in PBS. The descending aorta of each anesthetized mouse was transected, the bile duct was clamped at its distal (intestinal) end, and a 30-gauge needle was used to inflate each pancreas through the common bile duct with $4 \mathrm{ml} 4^{\circ} \mathrm{C}$ islet medium comprised of RPMI 1640 containing $1.0 \mathrm{~g} \mathrm{NaHCO}_{3}, 10 \%$ FBS (S12450H, Atlanta Biologicals), $1 \mathrm{mM}$ Na-pyruvate, and penicillin/streptomycin. The islet medium was supplemented with $0.8 \mathrm{mg} / \mathrm{ml}$ collagenase P (11-249002-001, Roche) and filtered at $0.22 \mu \mathrm{m}$ prior to injection. Subsequently, 2-3 excised pancreata were placed in separate $50 \mathrm{ml}$ conical centrifuge tubes and incubated in $5 \mathrm{ml}$ islet medium for 13 minutes at $37^{\circ} \mathrm{C}$. The medium was then decanted, fresh $4^{\circ} \mathrm{C}$ islet medium was added, and the tubes were shaken vigorously to disrupt the pancreata. The tissue suspensions were filtered through a 30-mesh metal screen to remove large debris, the filtrates were pelleted by centrifugation, and the pellets resuspended in $4^{\circ} \mathrm{C}$ islet medium. The resuspended material was centrifuged through Histopaque 1077 to isolate the islets, which were washed, resuspended in islet medium, and placed in a tissue culture incubator. After all pancreata were processed, the isolated islets were hand picked.

Isolated islet in vitro experiment. Islets were cultured in RPMI (Invitrogen) supplemented with $10 \%$ pooled human serum, $100 \mu \mathrm{g} / \mathrm{ml}$ penicillin, $100 \mathrm{U} / \mathrm{ml}$ streptomycin, and $1 \mathrm{mM}$ Na-pyruvate (Invit- 
rogen), with or without $100 \mu \mathrm{g} / \mathrm{ml}$ of 4 -MU (Sigma-Aldrich) for 24 hours. At the same time, [H3]-glucosamine was added at a concentration of $40 \mu \mathrm{Ci} / \mathrm{ml}$ to islet cultures. After 24 hours, the islets were digested with pronase $(100 \mu \mathrm{g} / \mathrm{ml})$ in $0.5 \mathrm{M}$ Tris, $\mathrm{pH}$ 6.5, overnight at $37^{\circ} \mathrm{C}$. Following digestion, the pronase was inactivated by heating to $100^{\circ} \mathrm{C}$ for 20 minutes. Radiolabeled macromolecules were then recovered and separated from unincorporated precursor by precipitation on nitrocellulose membranes using slot blot analysis as described previously (48). Briefly, $200 \mu \mathrm{l}$ sample was added to an equal volume of $2 \%$ cetylpyridinium chloride (CPC) and $50 \mathrm{mM}$ $\mathrm{NaCl}$ buffer, and the solution blotted onto a $0.45-\mu \mathrm{m}$ nitrocellulose membrane (Schleicher and Schuell). The membrane was washed 6 times in 2\% CPC and $50 \mathrm{mM} \mathrm{NaCl}$ buffer and once in deionized water before air drying at room temperature overnight. Incorporation of $[3 \mathrm{H}]$-glucosamine into $\mathrm{HA}$ was measured by digesting an equivalent radiolabeled aliquot with Streptomyces hyaluronidase ( $2 \mathrm{U} / \mathrm{ml}$ ) for 24 hours at $37^{\circ} \mathrm{C}$ before slot blotting. HA was measured as the amount of hyaluronidase-sensitive material precipitated to the nitrocellulose membrane. To determine the amount of chondroitin sulfate and dermatan sulfate present in the sample, an equal aliquot of sample was adjusted to $\mathrm{pH} 8.0$ before digesting with chondroitin ABC lyase $(0.03 \mathrm{U} / \mathrm{ml})$ (North Star BioProducts). All scintillation counting was done on Beckman LS 6500 (Beckman Instruments).

Tissue processing and imaging. Tissues for histochemistry were taken from animals and immediately transferred into $10 \%$ neutral buffered formalin or methyl Carnoy's fixative. The tissue was processed to paraffin on a Leica ASP300 Tissue Processor (Leica Microsystems Inc.). Then, 5- $\mu$ m thick sections were cut on a Leica RM 2255 Microtome (Leica Microsystems Inc.).

All staining steps were performed on a Leica Bond Max automated immune histochemistry (IHC) stainer (Leica Microsystems Inc.). For HA affinity histochemistry, the Bond Intense R Detection Kit, a streptavidin-HRP system (Leica Microsystems Inc.), was used with $4 \mu \mathrm{g} / \mathrm{ml}$ biotinylated-HABP in $0.1 \%$ BSA-PBS as the primary antibody. The Bond Polymer Detection Kit was used for all other immunohistochemistry. This detection kit contains a goat anti-rabbit reagent conjugated to polymeric HRP and a rabbit anti-mouse post-primary reagent for use with mouse primary antibodies.

TSG6, CD44, and I $\alpha$ IHC required pretreatment using heatmediated antigen retrieval with EDTA at high $\mathrm{pH}$ (Bond Epitope Retrieval Solution 2) for 10 minutes. For TSG6 IHC, sections were incubated for 1 hour with rabbit anti-mouse TSG6 (RAM-1, generated in-house) at 1:1,000 in Bond Antibody Diluent. For CD44 IHC, sections were incubated for 30 minutes with $0.5 \mu \mathrm{g} / \mathrm{ml}$ rat antiCD44 clone IM7 (Thermo Scientific). For FOXP3, sections were incubated for 30 minutes with $8 \mu \mathrm{g} / \mathrm{ml}$ rat anti-FOXP3 clone FJK-16s (eBioscience). For CD45, sections were incubated for 1 hour with 1 $\mu \mathrm{g} / \mathrm{ml}$ mouse anti-CD45.1 clone A20 (BioLegend). For incubation, rabbit anti-rat IgG (Vector Labs) post-primary antibody was added, in lieu of the post-primary reagent from the kit. For I $\alpha$ I staining, sections were incubated for 30 minutes with a cocktail of $1 \mu \mathrm{g} / \mathrm{ml}$ each goat anti-heavy chain 1 and goat anti-heavy chain 2 (Santa Cruz Biotechnology). For incubation, rabbit anti-goat IgG (Vector Labs) postprimary antibody was added, in lieu of the post-primary reagent from the Bond Polymer Detection Kit.

CD3 IHC required pretreatment using heat-mediated antigen retrieval with EDTA at high pH (Bond Epitope Retrieval Solution 2) for 20 minutes. Subsequently sections were incubated with $2.5 \mu \mathrm{g} / \mathrm{ml}$ rabbit anti-CD3 (A0452, Dako), and detection was performed using the Bond Polymer Refine Detection Kit. Versican immunohistochemistry required pretreatment with $0.2 \mathrm{U} / \mathrm{ml}$ chondroitinase $\mathrm{ABC}$ (C3667, Sigma-Aldrich) in a buffer containing $18 \mathrm{mM}$ Tris, $1 \mathrm{mM}$ sodium acetate, and $1 \mathrm{mg} / \mathrm{ml} \mathrm{BSA,} \mathrm{pH} \mathrm{8.0,} \mathrm{for} 1$ hour at $37^{\circ} \mathrm{C}$. After digestion, the sections were incubated for 1 hour with $3 \mu \mathrm{g} / \mathrm{ml}$ rabbit anti-mouse versican (GAG $\beta$-domain) (AB1033, Millipore) in Bond Antibody Diluent, and detection was performed using the Bond Polymer Refine Detection Kit.

The paraffin slides for the immune fluorescence HA staining were deparaffinized in xylene and were diluted into PBS in descending concentrations of ethanol. The slides were then rinsed several times in PBS and blocked in 4\% BSA for 5 hours. The tissues were probed with $4 \mu \mathrm{g} / \mathrm{ml} \mathrm{HABP}$ in blocking medium, overnight at room temperature. The slides were rinsed in PBS for 30 minutes, before the secondary Streptavidin (S32354, Molecular Probes) was used at 1:400 for 2 hours. The slides were rinsed in PBS, and the nuclei were stained with Propidium Iodide (P3566, Molecular Probes) at 1:200. The Propidium Iodide was mixed into the mounting medium with Prolong Gold Antifade (P36930, Molecular Probes).

All images were visualized using a Leica DMIRB inverted fluorescence microscope equipped with a Pursuit 4-megapixel cooled color/monochrome charge-coupled device camera (Diagnostic Instruments). Images were acquired using the Spot Pursuit camera and Spot Advance Software (SPOT Imaging Solutions; Diagnostic Instruments). Image analysis was performed using Image (NIH), as described previously (6).

Real-time quantitative PCR. Islets were harvested for total RNA isolation using the High Pure RNA Isolation Kit (Roche Applied Science) and reverse transcribed using the High-Capacity cDNA Reverse Transcription Kit (Applied Biosystems). For real-time quantitative PCR, all reagents were supplied by Applied Biosystems, unless otherwise noted. Relative quantification of Has1, Has2, Has3, Hyal1, Hyal2, IaI, Rhamm, and versican gene expression was performed using TaqMan Gene Expression Assays (Applied Biosystems): Has1, Mm00468496_ m1; Has2, Mm00515089_m1; Has3, Mm00515092_m1; Hyal1, Mm00476206_m1; Hyal2, Mm01230689_g1; IaI, Mm01277164_m1; Rhamm, Mm00469183_m1; and versican, Mm01283063_m1. Briefly, 100 ng cDNA was amplified in 1X TaqMan Gene Expression Master Mix (Applied Biosystems) with a $250 \mathrm{nM}$ TaqMan probe (Applied Biosystems) in a $20 \mu \mathrm{l}$ reaction. Amplification of TSG6, insulin, and layilin was performed using $100 \mathrm{ng}$ cDNA in 1X Power SYBR Green PCR Master Mix (Applied Biosystems) and $1 \mu \mathrm{M}$ primer. Melting curve analysis confirmed that only one product was amplified. Expression was normalized to eukaryotic 18S rRNA Endogenous Control (4333760, Life Technologies). All reactions were run using the standard program for 50 cycles on an ABI7900HT thermocycler. All samples were performed in duplicate, and copy number estimates were generated from a standard curve created by using a selected reference cDNA template and TaqMan probe. Primers for TSG6 and insulin were designed with NCBI Primer-BLAST, synthesized by SigmaAldrich, and are as follows: TSG6F: 5'-ATTTGAAGGTGGTCGTCTCG-3', TSG6R: 5'-GTTTCACAATGGGGTATCCG-3', insulinF: 5'-GTTGGTGCACTTCCTACCCC-3', insulinR: 5'-CACACACCAGGTAGAGAGCC-3', layilinF: 5'-ATGACCGGTGCAACATGAAGA-3', and layilinR: 5'-GCTTCACCTCCAGGCCAAAT-3'. Data for mRNA 
expression are provided as mean \pm SEM of the estimated copy number, normalized to $18 \mathrm{~S}$ rRNA, and differences between enriched primary islet cell populations were analyzed.

Measurement of HA plasma levels. Samples were thawed and then assayed for HA levels in a single batch using a modified HA-ELISA (49). Each sample was analyzed in triplicate, with a mean value obtained for each individual.

$H A$ quantification. Tissues were first lyophilized and weighed and then were digested with proteinase $\mathrm{K}(250 \mu \mathrm{g} / \mathrm{ml})$ in $100 \mathrm{mM}$ ammonium acetate, $\mathrm{pH} 7.0$, overnight at $60^{\circ} \mathrm{C}$. After digestion, the enzyme was inactivated by heating to $100^{\circ} \mathrm{C}$ for 20 minutes. The total amount of HA was determined by a modified competitive ELISA in which the samples to be assayed were first mixed with biotinylated HA-binding protein and then added to HA-coated microtiter plates, the final signal being inversely proportional to the level of HA added to the bPG (50).

Statistics. Data are expressed as mean \pm SEM of $n$ independent measurements. Comparison between 2 groups was performed with unpaired 2-tailed $t$ tests. A $P$ value of less than 0.05 was considered statistically significant. Data analysis was performed with the use of GraphPad Prism 5.0 software.

Study approval. All animal experiments and procedures were approved by the Animal Care and Use Committee at the Benaroya Research Institute and/or at the Stanford University Medical School.
The study of human tissue samples was carried out with the approval of the Institutional Review Board of the Benaroya Research Institute.

\section{Acknowledgments}

Our thanks go to V. Green, J. Bollyky, M. Butte, H. Ishak, J. Sweere, S. Keswani, and C. Blish for their reading of the manuscript and their helpful comments. We also gratefully acknowledge C.G. Fathman's help with the NOD model. This work was supported in part by grants from the DFG (NA 965/2-1 to N. Nagy and KA 3441/1-1 to G. Kaber) and the NIH (R01 DK096087-01, R01 HL113294-01A1, and U01 AI101984 to P.L. Bollyky; U01 AI101990 Pilot Project; and a Building Interdisciplinary Research Team supplement [AR037296 to T.N. Wight]). This work was also supported by grants from the JDRF (nPOD 25-2010-648 to T.N. Wight and 3-PDF-2014-224A-N to N. Nagy) and Stanford SPARK. R.B. Vernon is supported by a major grant from the Klorfine Foundation. V.G. Sunkari was supported by a grant from the Larry Hillblom Foundation.

Address correspondence to: Paul L. Bollyky, 300 Pasteur Drive, Grant S-143A, Division of Infectious Diseases and Geographic Medicine, Department of Medicine, Stanford University School of Medicine, Stanford, California 94305-5107, USA. Phone: 650.723.3375; E-mail: pbollyky@stanford.edu.
1. Wildin RS, et al. X-linked neonatal diabetes mellitus, enteropathy and endocrinopathy syndrome is the human equivalent of mouse scurfy. Nat Genet. 2001;27(1):18-20.

2. Ziegler AG, Nepom GT. Prediction and pathogenesis in type 1 diabetes. Immunity. 2010;32(4):468-478.

3. Putnam AL, et al. Expansion of human regulatory T-cells from patients with type 1 diabetes. Diabetes. 2009;58(3):652-662.

4. Glisic S, Ehlenbach S, Jailwala P, Waukau J, Jana $\mathrm{S}$, Ghosh S. Inducible regulatory T cells (iTregs) from recent-onset type 1 diabetes subjects show increased in vitro suppression and higher ITCH levels compared with controls. Cell Tissue Res. 2010;339(3):585-595.

5. Zhou X, et al. Instability of the transcription factor Foxp3 leads to the generation of pathogenic memory T cells in vivo. Nat Immunol. 2009;10(9):1000-1007.

6. Bogdani M, et al. Hyaluronan and hyaluronan-binding proteins accumulate in both human type 1 diabetic islets and lymphoid tissues and associate with inflammatory cells in insulitis. Diabetes. 2014;63(8):2727-2743.

7. Jiang D, Liang J, Noble PW. Hyaluronan as an immune regulator in human diseases. Physiol Rev. 2011;91(1):221-264.

8. Plevris JN, et al. Serum hyaluronan - a noninvasive test for diagnosing liver cirrhosis. Eur J Gastroenterol Hepatol. 2000;12(10):1121-1127.

9. Colombaro V, et al. Inhibition of hyaluronan is protective against renal ischaemia-reperfusion injury. Nephrol Dial Transplant. 2013;28(10):2484-2493.

10. Day AJ, Prestwich GD. Hyaluronan-binding proteins: tying up the giant. J Biol Chem. 2002;277(7):4585-4588.
11. Choi H, Lee RH, Bazhanov N, Oh JY, Prockop DJ. Anti-inflammatory protein TSG-6 secreted by activated MSCs attenuates zymosan-induced mouse peritonitis by decreasing TLR2/NF- $\mathrm{BB}$ signaling in resident macrophages. Blood. 2011;118(2):330-338.

12. Kota DJ, Wiggins LL, Yoon N, Lee RH. TSG-6 produced by hMSCs delays the onset of autoimmune diabetes by suppressing Th1 development and enhancing tolerogenicity. Diabetes. 2013;62(6):2048-2058.

13. Wesley JD, Sather BD, Perdue NR, Ziegler SF, Campbell DJ. Cellular requirements for diabetes induction in DO11.10xRIPmOVA mice. JImmunol. 2010;185(8):4760-4768.

14. Kultti A, et al. 4-Methylumbelliferone inhibits hyaluronan synthesis by depletion of cellular UDP-glucuronic acid and downregulation of hyaluronan synthase 2 and 3. Exp Cell Res. 2009;315(11):1914-1923.

15. Atkinson MA, Leiter EH. The NOD mouse mode of type 1 diabetes: as good as it gets? Nat Med. 1999;5(6):601-604.

16. Bollyky PL, Bogdani M, Bollyky JB, Hull RL, Wight TN. The role of hyaluronan and the extracellular matrix in islet inflammation and immune regulation. Curr Diab Rep. 2012;12(5):471-480.

17. Hull RL, Johnson PY, Braun KR, Day AJ, Wight TN. Hyaluronan and hyaluronan binding proteins are normal components of mouse pancreatic islets and are differentially expressed by islet endocrine cell types. J Histochem Cytochem. 2012;60(10):749-760.

18. Eizirik DL, Colli ML, Ortis F. The role of inflammation in insulitis and $\beta$-cell loss in type 1 diabetes. Nat Rev Endocrinol. 2009;5(4):219-226.

19. Cheng G, Swaidani S, Sharma M, Lauer ME, Hascall VC, Aronica MA. Hyaluronan deposition and correlation with inflammation in a murine ovalbumin model of asthma. Matrix Biol. 2011;30(2):126-134.

20. Nagy N, et al. Inhibition of hyaluronan synthesis accelerates murine atherosclerosis: novel insights into the role of hyaluronan synthesis. Circulation. 2010;122(22):2313-2322.

21. Miyazaki A, et al. Predominance of T lymphocytes in pancreatic islets and spleen of pre-diabetic non-obese diabetic (NOD) mice: a longitudinal study. Clin Exp Immunol. 1985;60(3):622-630.

22. McKallip RJ, Do Y, Fisher MT, Robertson JL, Nagarkatti PS, Nagarkatti M. Role of CD44 in activation-induced cell death: CD44-deficient mice exhibit enhanced $\mathrm{T}$ cell response to conventional and superantigens. Int Immunol. 2002;14(9):1015-1026.

23. Haxhinasto S, Mathis D, Benoist C. The AKTmTOR axis regulates de novo differentiation of CD4 ${ }^{+}$Foxp $^{+}$cells. JExp Med. 2008;205(3):565-574.

24 . Luo X, et al. Cutting edge: TGF- $\beta$-induced expression of Foxp 3 in T cells is mediated through inactivation of ERK. JImmunol. 2008;180(5):2757-2761.

25. Bollyky PL, et al. ECM components guide IL-10 producing regulatory T-cell (TR1) induction from effector memory T-cell precursors. Proc Natl Acad Sci U S A. 2011;108(19):7938-7943.

26. Bollyky PL, et al. CD44 costimulation promotes FoxP3+ regulatory $\mathrm{T}$ cell persistence and function via production of IL-2, IL-10, and TGF- $\beta$. J Immunol. 2009;183(4):2232-2241.

27. Bollyky PL, Falk BA, Wu RP, Buckner JH, Wight TN, Nepom GT. Intact extracellular matrix and the maintenance of immune tolerance: high molecular weight hyaluronan promotes persistence of induced $\mathrm{CD} 4{ }^{+} \mathrm{CD} 25^{+}$regulatory T cells. JLeukoc Biol. 2009;86(3):567-572. 
28. Oberg HH, Ly TT, Ussat S, Meyer T, Kabelitz D, Wesch D. Differential but direct abolishment of human regulatory $\mathrm{T}$ cell suppressive capacity by various TLR2 ligands. J Immunol. 2010;184(9):4733-4740.

29. Sutmuller RP, et al. Toll-like receptor 2 controls expansion and function of regulatory $\mathrm{T}$ cells. JClin Invest. 2006;116(2):485-494.

30. Feuerer M, Shen Y, Littman DR, Benoist C, Mathis D. How punctual ablation of regulatory $\mathrm{T}$ cells unleashes an autoimmune lesion within the pancreatic islets. Immunity. 2009;31(4):654-664.

31. Grinberg-Bleyer Y, et al. IL-2 reverses established type 1 diabetes in NOD mice by a local effect on pancreatic regulatory T cells. JExp Med. 2010;207(9):1871-1878.

32. Baranova NS, et al. The inflammation-associated protein TSG- 6 cross-links hyaluronan via hyaluronan-induced TSG- 6 oligomers. J Biol Chem. 2011;286(29):25675-25686.

33. Hull RL, Peters MJ, Perigo SP, Chan CK, Wight TN, Kinsella MG. Overall sulfation of heparan sulfate from pancreatic islet $\beta$-TC3 cells increases maximal fibril formation but does not determine binding to the amyloidogenic peptide islet amyloid polypeptide. J Biol Chem. 2012;287(44):37154-37164.

34. Bitan M, et al. Heparanase prevents the development of type 1 diabetes in non-obese diabetic mice by regulating T-cell activation and cytokines production. Diabetes Metab Res Rev. 2008;24(5):413-421.

35. Irving-Rodgers HF, et al. Molecular composition of the peri-islet basement membrane in NOD mice: a barrier against destructive insulitis. Diabetologia. 2008;51(9):1680-1688.

36. Ziolkowski AF, Popp SK, Freeman C, Parish CR, Simeonovic CJ. Heparan sulfate and heparanase play key roles in mouse $\beta$ cell survival and autoimmune diabetes. J Clin Invest. 2012;122(1):132-141.

37. Parish CR, et al. Unexpected new roles for heparanase in Type 1 diabetes and immune gene regulation. Matrix Biol. 2013;32(5):228-233.

38. Uchakina ON, Ban H, McKallip RJ. Targeting hyaluronic acid production for the treatment of leukemia: treatment with 4-methylumbelliferone leads to induction of MAPK-mediated apoptosis in K562 leukemia. Leuk Res. 2013;37(10):1294-1301.

39. Arai $\mathrm{E}$, et al. Inhibition of hyaluronan retention by 4-methylumbelliferone suppresses osteosarcoma cells in vitro and lung metastasis in vivo. Br JCancer. 2011;105(12):1839-1849.

40. Urakawa $\mathrm{H}$, et al. Inhibition of hyaluronan synthesis in breast cancer cells by 4 -methylumbelliferone suppresses tumorigenicity in vitro and metastatic lesions of bone in vivo. Int J Cancer. 2012;130(2):454-466.

41. McKallip RJ, Ban H, Uchakina ON. Treatment with the hyaluronic acid synthesis inhibitor 4-methylumbelliferone suppresses LPSinduced lung inflammation. Inflammation. 2015;38(3):1250-1259.

42. Yoshioka Y, et al. Suppression of hyaluronan synthesis alleviates inflammatory responses in murine arthritis and in human rheumatoid synovial fibroblasts. Arthritis Rheum.
2013;65(5):1160-1170.

43. Mueller AM, Yoon BH, Sadiq SA. Inhibition of hyaluronan synthesis protects against central nervous system (CNS) autoimmunity and increases CXCL12 expression in the inflamed CNS. J Biol Chem. 2014;289(33):22888-22899.

44. Garrett ER, Venitz J, Eberst K, Cerda JJ. Pharmacokinetics and bioavailabilities of hymecromone in human volunteers. Biopharm Drug Dispos. 1993;14(1):13-39.

45. Abate A, et al. Hymecromone in the treatment of motor disorders of the bile ducts: a multicenter, double-blind, placebo-controlled clinical study. Drugs Exp Clin Res. 2001;27(5-6):223-231.

46. Bluestone JA, Herold K, Eisenbarth G. Genetics, pathogenesis and clinical interventions in type 1 diabetes. Nature. 2010;464(7293):1293-1300.

47. Bollyky PL, et al. The toll-like receptor signaling molecule Myd88 contributes to pancreatic betacell homeostasis in response to injury. PLoS One. 2009;4(4):e5063.

48. Agren UM, Tammi R, Tammi M. A dot-blot assay of metabolically radiolabeled hyaluronan. Anal Biochem. 1994;217(2):311-315.

49. Potter-Perigo S, et al. Polyinosine-polycytidylic acid stimulates versican accumulation in the extracellular matrix promoting monocyte adhesion. $\mathrm{Am}$ JRespir Cell Mol Biol. 2010;43(1):109-120.

50. Mapleson JL, Buchwald M. Effect of cycloheximide and dexamethasone phosphate on hyaluronic acid synthesis and secretion in cultured human skin fibroblasts. J Cell Physiol. 1981;109(2):215-222. 